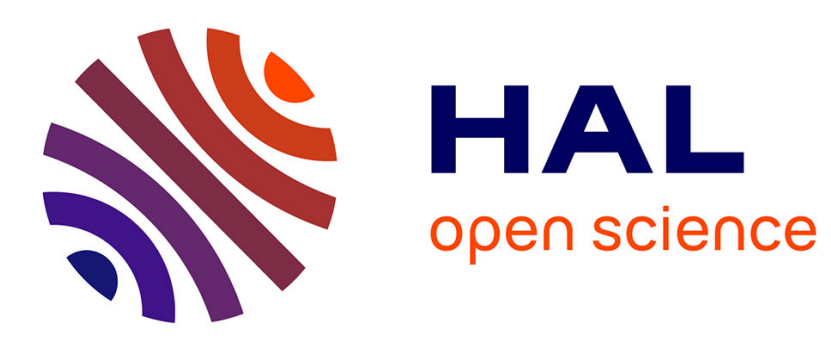

\title{
Brecciation-related argon redistribution in alkali feldspars: An in naturo crushing study
}

\author{
Nicolas Arnaud, Elizabeth Eide
}

\section{To cite this version:}

Nicolas Arnaud, Elizabeth Eide. Brecciation-related argon redistribution in alkali feldspars: An in naturo crushing study. Geochimica et Cosmochimica Acta, 2000, 64 (18), pp.3201-3215. hal-00198283

\section{HAL Id: hal-00198283 \\ https://hal.science/hal-00198283}

Submitted on 18 Dec 2007

HAL is a multi-disciplinary open access archive for the deposit and dissemination of scientific research documents, whether they are published or not. The documents may come from teaching and research institutions in France or abroad, or from public or private research centers.
L'archive ouverte pluridisciplinaire HAL, est destinée au dépôt et à la diffusion de documents scientifiques de niveau recherche, publiés ou non, émanant des établissements d'enseignement et de recherche français ou étrangers, des laboratoires publics ou privés. 


\title{
Brecciation-related argon redistribution in alkali feldspars: an in naturo crushing study
}

\author{
Nicolas O. Arnaud and Elizabeth A. Eide
}

\section{Abstract}

Alkali feldspar thermochronologic modeling with the ${ }^{40} \mathrm{Ar} /{ }^{39} \mathrm{Ar}$ method has generated marked advances in knowledge of the mechanisms for argon diffusion in feldspars. While the goal in many cases has been to extrapolate the observed and modeled argon behavior in feldspars to natural geological settings, scientific debate surrounding the true feasibility of such extrapolations and indeed, the validity of thermochronologic modeling in itself, have provided much impetus to improve laboratory techniques to test, and increase basic understanding of, argon diffusion. Two cornerstones for the debate over the feasibility of alkali feldspar thermochronology for modeling natural, geologic processes have been: 1) Is volume diffusion the main mechanism for argon movement in feldspars?, and 2) If volume diffusion is a viable mechanism, does argon then reside in discrete 'domains' within the feldspar lattice?

We describe a study of alkali feldspars from a profile through a well-controlled brittle fault zone in western Norway; the feldspars document argon loss during deformation and strongly suggest the existence of argon 'domains' within the feldspars, at least during laboratory step heating. The progressive change in the character of argon diffusion is recognizable in the $\log r / \mathrm{r}_{\mathrm{o}}$ diffusion data from the feldspars and is mimicked by physical changes observed optically in the feldspars through progressive degrees of brittle deformation. Modeling results indicate a reduction in size of the biggest domains and the appearance of smaller domains during the strongest stages of deformation. Whether or not this reveals the existence and the transformation of the domain structure in naturo is difficult to prove from our data alone, but interestingly, this behaviour corresponds directly to the physical (optical) appearance of more intense crack networks and subgrains in progressively more brecciated feldspars. Because the thermochronologic histories derived from modeling the feldspar data conform very well to the known tectonic history of the area, the feldspars appear to have successfully retained physical (optical and isotopic) records of episodic tectonic processes operating from ductile through low-temperature brittle regimes in rocks with a Caledonian history overprinted by several later (younger) geologic events. However, because the 'cold' brecciation is the last tectonothermal event recorded by these rocks, it is impossible to truly test for the existence of diffusion domains in naturo. Argon loss appears to have been effective only in the most highly brecciated (deformed) samples where the combination of the connected crack network, increased fluid flow and higher temperatures enhanced diffusion via fast diffusion pathways and thus, volume diffusion from the lattice. Only minor argon loss occurred in zones of lower brittle strain, although some development of cracks and brittle features is evident. Independent of the existence of diffusion domains, this study highlights the possible pitfalls when cooling histories are deduced from brecciated feldspars in which age and diffusion charateristics have been decoupled: 
Feldspar brecciation, Arnaud and Eide while the geochronological memory has survived and is identical to that of nonbrecciated feldspars (suggesting no loss and minor effects of deformation), the diffusion characteristics have been completely transposed by brecciation and the appearance of new domains. Modeling feldspars with these latter characteristics would effectively utilise a new feldspar diffusion structure with an 'old' (relict) age memory.. 


\section{INTRODUCTION}

While the potential of alkali feldspar to retain geochronological as well as thermal information has long been known and used (Albarède et al., 1978, Zeitler, 1987) based on the closure temperature principle (Dodson, 1973), only recently were feldspars also proposed to be especially efficient in retaining a continuous thermal record. The latter could be safely extracted through complex modeling based upon the concept of "multi domain theory" (later referred to as MDD). Numerous studies have been conducted both to address and challenge the real thermochronologic potential of feldspars. Following upon the early studies of Harrison and Lovera (e.g. Harrison et al., 1991; Lovera et al., 1989, 1991), most work germaine to this issue has essentially focused on laboratory tests of the nature of diffusion in feldspars in vacuo, on the structural complexities of feldspars, and on the potential flaws and artefacts in the recovery of meaningful diffusion characteristics from this mineral (e.g. Harrison et al., 1993; Lovera et al., 1993, Parsons et al., 1991; Villa, 1994; Arnaud and Kelley, 1997, Reddy et al., 1998, Parsons et al., 1999). At the same time, several significant geological applications have indicated that the recovery of temperature/time paths from feldspars can be geologically realistic, especially when the derived paths have corroborated other independent, temperature-time evidence from the associated field geology (Harrison 1990; Arnaud et al., 1993; Leloup et al., 1995). Implicit in these studies has been the presumption that 1-laboratory experiments are representative of the same diffusion processes that occurred in nature at the geologic times represented by the data, 2- that diffusion domains originated in nature and not during laboratory treatment and 3- that most domains originate in nature at temperatures in agreement with the record of the thermal history. In this regard, while the nature of diffusion and the existence of diffusion domains can be challenged and tested in the laboratory, similar sorts of tests can rarely be conducted in the natural environment. Thus, while the recovery of geologically meaningful thermal histories is by itself a significant step toward validating the extrapolation of laboratory experiments to the natural environment and providing field evidence of natural diffusion in feldspars, we still lack critical documentation of the existence and behaviour of the multidomain structure of feldspars from direct diffusion studies induced in nature, by real geological processes.

The existence of domains controlling argon diffusion in feldspars was probably first suggested by Zeitler (1987) and subsequently re-enforced by Harrison, Lovera and co-workers. At the root of this theory is the assumption that argon loss is controlled essentially by lattice volume diffusion which takes the mathematical form $\frac{D}{r^{2}}=\frac{D_{o}}{r^{2}} e^{-\frac{E}{R T}}$ (where Do is the frequency factor, $\mathrm{r}$ is the typical size of the diffusing cell, $\mathrm{E}$ is the activation energy, $\mathrm{R}$ is the rare gas constant, and $\mathrm{T}$ is the absolute temperature). The initial observation was that the diffusivities, $\mathrm{D} / \mathrm{r}$, of argon measured during in vacuo step heating of feldspars seemed to drop suddenly and systematically to lower values (thus slower diffusion) with increasing temperatures; normally, if only $\mathrm{T}$ dominates the diffusion process, the opposite relationship would be expected (i.e. faster diffusion at higher T). Key observations (Lovera et al., 1991, 1993) related to this 
laboratory phenomenon were that the downward shift in $\mathrm{D} / \mathrm{r}$ was reproducible, but that high diffusivities at low temperatures seemed to vanish when step heating was repeated on the same sample. Given that $E$ and $D_{0}$ are theoretically intrinsic parameters of the crystal lattice, the logical explanation was that argon was extracted at low and high temperatures from different discrete domains which could be selectively emptied and which differed in size. The terminology "domain" was thus initially used to describe a mathematical explanation for decreasing diffusivities while temperature increased; this served to provide an explanation for the only variables not fixed a priori in the model ( "T" and "r"). At this point it seemed that the domains could, therefore, be viewed as real physical entities within feldspar grains. This assumption was repeatedly tested in numerous ways (e.g. Fitzgerald and Harrison, 1993; Lovera et al., 1993, Arnaud and Kelley, 1997) but, despite the variety of textural microstructures in feldspars represented in these studies, it proved difficult to match perfectly the range of sizes obtained through diffusion studies with real physical candidates in the feldspar structure. Moreover, this simple mathematical definition was later amended to imply the possibility that some domains might differ also in activation energy, thus implicitly divorcing the term "domain" from a clear physical meaning. In our own experience the use of multi-activation energy does not significantly enhance the modeling accuracy. moreover several studies suggest that indeed the appearing variation in activation energy could be largely due to artifact, such as multiple diffusion mechanisms (Lee, 1995) or unretentive low temperature domains never completely individualized during analysis (Lovera et al., 1997). We thus consider the original concept of doamins to remain largely valid. Moreover since we claim in this study to identify a size reduction effect of the domains during brecciation we will use this term implicitely assuming that it describes a zone of the lattice, of a specific size, limited by coherent boundaries allowing direct diffusion to the surface of the grain when argon has reached the border of that zone. Those domains should not be nested and the lattice characteristics will remain constant from one domain to another.

In addressing the existence of feldspar domains, in vacuo crushing experiments have been highly valuable to demonstrate that crushing physically affects the domain structure in feldspars by reducing the size of the biggest domains, originally presumed to be about the same size as the individual grain (Lovera et al., 1993). This type of behaviour during laboratory crushing has precipitated two further questions: 1) Can natural crushing during, for example, brecciation, affect argon loss in feldspars in a similar way, and 2) Can examples of natural crushing reveal the indisputable existence of domains during the geological evolution of the feldspars? The influence of natural brecciation, and of deformation as a whole, on argon retention has been repeatedly questioned, but rarely has the evidence led to a clear conclusion (Tullis and Yund, 1991, 1996). This study addresses several of these unresolved issues by examining the domain structure and related age information retained by feldpars near a well-studied brecciation zone in western Norway. By modeling and comparing diffusion in feldspars remote from, and within, the brecciation zone, we derive a hypothesis about the effect of natural brecciation on the intimate argon diffusion-related structures in the feldspars and 
propose some clarification of the kinetics and physical processes potentially involved in argon loss during brittle deformation.

\section{GEOLOGICAL BACKGROUND}

${ }^{40} \mathrm{Ar} /{ }^{39} \mathrm{Ar}$ thermochronologic data from reactivated portions of the Nordfjord-Sogn Detachment Zone (NSDZ, Fig. 1) and the Dalsfjord Fault (DF) in the Sunnfjord region of western Norway demonstrate punctuated, late Palaeozoic through Mesozoic tectonothermal activity in the area (Eide et al. 1997, 1999). ${ }^{40} \mathrm{Ar} /{ }^{39} \mathrm{Ar}$ ages from white mica, biotite and amphibole are consistent with maintenance of a low geothermal gradient associated with Caledonian (late Silurianearly Devonian) collision and rapid removal of $>60 \mathrm{~km}$ of crustal overburden by middle Devonian time (Andersen et al., 1998; Fossen and Dunlap, 1998; Dunlap and Fossen, 1998; Eide et al., 1999). The NSDZ developed in early Devonian time as a major extensional detachment along which high-pressure, Caledonized basement was eventually juxtaposed against overlying low-grade nappe sequences (Andersen and Jamtveit, 1990; Osmundsen et al., 1998). Diffusion and thermal modeling of K-feldspars sampled in a profile through the NSDZ has extended the knowledge of low-temperature $\left(<300^{\circ} \mathrm{C}\right)$ activity along the NSDZ and reveals an Early Carboniferous (360 to $\left.340 \mathrm{Ma}\right)$ rapid cooling event (detailed later herein and in Eide et al., 1999), associated with an episode of rapid unroofing. Brittle reactivation of the initially ductile detachment zone is constrained to two episodes, one in latest Permian time (ca. 250-260 Ma) and another in latest Jurassic-early Cretaceous time (135-160 Ma). These brittle reactivation events correspond directly to the well-documented periods of rift-related, sedimentary basin-forming activity in the North Sea (e.g. Færseth 1996) and to extension-related dyke emplacement elsewhere in western Norway (Færseth et al., 1976; Torsvik et al. 1997). The brittle fault which is the focus of our study retains a well-developed green fault breccia previously dated to correspond to the latest Permian episode of regional extension (Torsvik et al., 1992; Eide et al., 1997) (Fig.1). Field relationships and documentation of the ages of these young, brittle faulting events are detailed in Brekke and Solberg (1987) Torsvik et al. (1992) and Eide et al. (1997).

The previous work on feldspars sampled in a profile through the NSDZ demonstrated very consistent argon release patterns and modeled cooling histories (Eide et al. 1999). The domains modeled for the feldspars correspond to distinct changes in late Palaeozoic cooling rates: 1 ) slow cooling at $0.5-2.2^{\circ} \mathrm{C} / \mathrm{m} . \mathrm{y}$. from ca. 380 to $360 \mathrm{Ma}$; 2) rapid cooling at ( $>15^{\circ} \mathrm{C} / \mathrm{m} . \mathrm{y}$. in Early Carboniferous time,360-340 Ma); 3) slow cooling at $0.4-1.7^{\circ} \mathrm{C} / \mathrm{m} . \mathrm{y}$. after c. $340 \mathrm{Ma}$, with partial Ar-loss in Permian and late Jurassic-early Cretaceous times. The older episode of slow cooling followed upon exhumation of the basement + nappes immediately after collision (feldspars exhibit high-temperature plateaus at ca. 384-419 Ma, in concert with other age and tectonostratigraphic data). The Early Carboniferous rapid cooling event recorded by the feldspars links the western Norway margin to contemporaneous unconformities, regional extension, 
basin inversion and igneous activity previously identified around the proto-North Atlantic perimeter; in western Norway, this Early Carboniferous event is linked to an episode of rapid unroofing (Eide et al., 1999). The second, younger period of slow cooling modeled in the feldspars shows evidence for disruption by brittle reactivation events, outlined above and herein, in latest Palaeozoic and Mesozoic times.

The geochronological information previously recovered from these breccias is in agreement with all available geological information both on- and offshore; thus we proceed with confidence upon the assumption that the retention of the geochronological information in the feldspars within the breccia was dominated by microstructural processes in synergy with macro-structural developments. In turn, this implies that deformation on the rock scale should be associated with significant and reproducible intra-crystalline processes that had bearing on argon loss.

\section{SAMPLE DESCRIPTIONS}

The fault-breccia zone in western Norway comprises a green network breccia and a cross-cutting red breccia. The latter is a 15 to 35 cm-thick package, with orientation 210/10W and separates 'hanging-wall' from 'footwall' green network breccias (Brekke and Solberg, 1987; Torsvik et al., 1992). The hanging-wall green breccia reworked rocks of the Dalsfjord mangerite suite (Fig.1). Macroscopically, the green breccia is a relatively confined zone ca. $5 \mathrm{~m}$ thick; however, we note (see also below) that the total zone of rock mass affected by brecciation (as evidenced microscopically) is broader.

The Dalsfjord ‘mangerite suite’ comprises deep-seated plutonic rocks ranging from mangerite through gabbro to syenite (Kolderup 1921; Brekke and Solberg 1987). Dating the time of intrusion of these rocks has proven difficult, but Early Proterozoic ages are probable. The mangerite resides within a nappe package that underwent low-greenschist facies metamorphism during its eastward obduction onto the margin of Baltica between 445 and 450 Ma (Andersen et al. 1998), prior to Caledonian continental collision.

In order to test for potential variations in the domain structure of brecciated feldspars, we analysed three Kfeldspars from the mangerite suite from sites at selected distances from the main fault breccia. Samples were taken: 1) ca. $4 \mathrm{~km}$ (map distance) from the brittle fault/brecciation zone (95AS1, subsequently called the 'unbrecciated' sample), 2) ca. $100 \mathrm{~m}$ from the brittle fault (95AS3, 'slightly brecciated'), and 3) within the breccia itself (95AS4B, 'brecciated') (see Fig.1). The structural (vertical) distance from the fault breccia represented by the slightly brecciated sample is about $20 \mathrm{~m}$. We estimate the structural distance between the fault breccia and the unbrecciated sample to be more than $200 \mathrm{~m}$. The textures of the rocks and their feldspars show a clear inverse relationship between degree of brittle deformation and distance from the fault breccia. Table 1 contains chemical compositions of feldspars discussed below. 
Our unbrecciated sample (95AS1) has a primary assemblage of coarse-grained perthitic microcline, plagioclase, quartz, titanite, relict pyroxene replaced by chlorite, Fe-Ti oxides, and accessory garnet; a secondary, greenschist facies assemblage with chlorite, white mica, minor biotite, epidote, titanite, calcite and apatite occurs in small patches. The interiors of alkali feldspar $\left(\mathrm{Or}_{96-98} \mathrm{Ab}_{2-4}\right)$ contain albite lamellae $\left(\mathrm{Or}_{1-3} \mathrm{Ab}_{97-99}\right)$ or more rarely, coarser, albite blebs; rims of alkali feldspars are free of lamellae and inclusions and may be slightly more Na-rich $\left(\mathrm{Or}_{95} \mathrm{Ab}_{5}\right)$ (Table 1$)$. The matrix plagioclase porphyroblasts $\left(\mathrm{Ab}_{98-99} \mathrm{Ab} \mathrm{b}_{0-1}\right)$ are clouded by fine-grained white micas. While the subhedral quartzofeldspathic minerals form a generally coarse, interlocking texture, inspection of fine-scale features reveals some irregular to serrated grain boundaries, minor undulatory extinction, minor subgrain development at alkali feldspar rims, strained twins in plagioclase, and polygonal quartz rinds around some alkali-feldspar porphyroblasts (Fig. 2a). The rock texture and secondary mineral assemblage are most likely related to the low-temperature greenschist metamorphism and mild deformation associated with eastward emplacement/obduction of the entire nappe package in Ordovician times, although earlier deformation/metamorphism (between Precambrian and late Ordovician) is also possible. This grainscale plastic deformation was obviously only partially recovered. Very weak evidence of brittle deformation is observed in the form of scattered microcracks in feldspar porphyroblasts.

The slightly brecciated sample (95AS2) is similar mineralogically to the unbrecciated sample but retains evidence both for ductile (early) and brittle (late) grain-scale deformation. Generally, microperthitic alkali feldspar is somewhat turbid and plagioclase porphyroblasts are nearly occluded by fine-grained white mica inclusions. The greenschist facies assemblage is more extensively developed in this sample: clusters of epidote grains and chlorite patches are scattered throughout the section and dark stringers and brittle fractures contain an assemblage of oxides + titanite + epidote. Alkali feldspars $\left(\mathrm{Or}_{98} \mathrm{Ab}_{2}\right)$ contain deformed albite lamellae and again, rare, coarse, subrounded albitic blebs (Table 1). Grain boundaries of quartz and feldspar porphyroblasts are serrated and subgrain growth is both more developed and irregularly distributed at grain boundaries as well as in the interiors of grains compared to the unbrecciated sample. Undulatory extinction is common in both quartz and alkali feldspars and is not affected by subgrain limits. Brittle deformation is manifested in the alkali feldspars as fractures/cracks that crosscut individual porphyroblasts and/or that visibly offset portions of single grains (with albite lamellae serving as offset markers); stairstep fractures are also evident (Fig. 2b). In selected instances, albite lamellae that have been intersected by cracks appear to curve into the plane of the crack, indicating some degree of plastic flow or recovery during deformation.

Some of the throughgoing cracks and fractures link directly to veinlets of greenschist facies material on the rims of feldspar porphyroblasts and indicate contemporaneous fluid activity during brittle fracturing. Scattered patches of cataclastic material vary from angular fragments to milled, rounded grains of feldspar + quartz whose sizes range from recognizable minerals down to sub-microscopic, isotropic crush material. These cataclastic patches are typically bounded by thin strings of greenschist facies minerals and we observe partial orientation of the long axes of larger 
feldspar fragments along these strings. The rock texture and secondary mineral assemblage represent a combination of ductile deformation/low-temperature metamorphism during Caledonian or earlier processes (witness the sample’s proximity to the extensional, Devonian NSDZ), and partially recovered brittle deformation affected during the Permian and latest Jurassic brecciation episodes (see Fig. 1).

In the brecciated sample (95AS4B), angular alkali feldspar clasts are surrounded by anastomosing veinlets comprising fine, feldspar fragments, chlorite, epidote, titanite, magnetite and fine-grained, layer silicates. The angular feldspars themselves are composed almost exclusively of weakly visible, large, sub-grains with preserved perthitic feldspar cores containing deformed or ‘wormy’ albite lamellae. In some relict grains, the typical ‘crosshatch’ twinning of the microclines appears skewed.

Cataclasis and autocataclasis produced dramatic grain-size reduction in this rock, compared to the other two samples. Cataclasis was localised initially along grain boundaries between quartzofeldspathic minerals; the cataclastic activity facilitated propagation of fractures through weakened grains which subsequently induced a significant amount of autocataclasis (Fig. 2c, 2d). Occurrence of new, replacement minerals like quartz and albite on and in the alkali feldspars is evident, especially near areas of pronounced grain reduction. Finer-grained, disaggregated feldspar fragments float in the greenschist-facies 'matrix'; importantly, fine-grained magnetite, dated palaeomagnetically to late Permian in this green breccia (Torsvik et al., 1992) has crystallised in this matrix, in veinlets and in the cataclastic zones, attesting to both the timing (Late Permian) and temperature $\left(<250^{\circ} \mathrm{C}\right)$ of breccia formation.

The basic grain-scale evolution of brittle deformation in these rocks from 'unbrecciated' through to the breccia sensu stricto, is one where minor fracturing is progressively replaced by micro-crushing. While the exact slip systems producing the observed features in these grains cannot be positively addressed without TEM analysis, the rocks closer to the brittle fault have probably been influenced by both microcracking and dislocation creep. Although the latter is usually affected only at higher temperatures (amphibolite facies or more), the presence of water, as evidenced from the contemporary low-greenschist facies mineral assemblage in the brittley deformed rocks, may have facilitated the transition between these two grain-scale mechanisms. The partial strain recovery exhibited by both the brecciated and the partially brecciated samples was almost certainly aided by the presence of low-temperature fluids throughout the fracture process (see also Tullis and Yund, 1996).

\section{ARGON LOSS FROM THE SAMPLES}

\section{Analytical procedures}

Whole rocks were crushed, sieved and washed; individual grains of feldspar were hand-picked for analysis after examination under binocular microscope. The whole analytical treatment is described in Eide et al. (1999). Bulk 
mineral separates were irradiated in a single irradiation, at the Siloée reactor of Centre d'Etude Atomique in Grenoble France. The J-factor value of 0.006764 (with $1 \%$ relative standard deviation) was estimated by the use of duplicates of the Caplongue amphibole standard with an age of 344.5 Ma (Maluski and Schaeffer, 1982). Interfering nuclear reactions on $\mathrm{K}$ and $\mathrm{Ca}$ were calculated by co-irradiation of pure salts but their effect is negligible owing to the K-rich chemistry of the analyzed feldspars. Samples were loaded in aluminium packets into a double vacuum furnace with furnace temperature calibration by means of a thermocouple fitted at the base of an Mo crucible. Samples were then cyclically heated from 400 or $450^{\circ} \mathrm{C}$ to $1400^{\circ} \mathrm{C}$ (see Lovera et al., 1997 and Fig. 3). The initial steps between $400^{\circ} \mathrm{C}$ and $650^{\circ} \mathrm{C}$ are duplicated in order to identify more clearly the presence of excess argon that might be hosted in fluid inclusions or low retentivity sites (Harrison et al., 1994), while steps between 700 and $800^{\circ} \mathrm{C}$ are cycled in order to extract the most potentially useful information about argon diffusion (Lovera et al. 1989, 1991). Heating schedules for each sample are detailed in Table 2.

Individual gas steps were purified by means of a cold trap with liquid air and SAES TM Al-Zr getters. Once cleaned, the gas was introduced into a VG3600 mass spectrometer, with 2 minutes for gas equilibration prior to analysis in static mode. Signals were measured by means of a Faraday cup with a resistor of $10^{11}$ ohm for ${ }^{40} \mathrm{Ar}$ and ${ }^{39} \mathrm{Ar}$, while ${ }^{38} \mathrm{Ar},{ }^{37} \mathrm{Ar}$ and ${ }^{36} \mathrm{Ar}$ were analysed with a photomultiplier after interaction on a Daly plate. Gain between both collectors was estimated by duplicate analysis of ${ }^{39} \mathrm{Ar}$ on both during each analysis, and also by statistical calibration done over a period of several years. During the course of analysis, the gain values average 92.5 and are known at better than $1.5 \%$. This error is included in the age calculation, along with analytical errors on each signal and errors on the blank values. Variations in $\mathrm{Cl} / \mathrm{K}$ ratios through the degassing process are monitored through neutron induced ${ }^{38} \mathrm{Ar} /{ }^{39} \mathrm{Ar}$ isotope ratios where ${ }^{38} \mathrm{Ar}$ is derived from $\mathrm{Cl}$. The connection between those ratios is semi-qualitative as no multiplicative factor was calculated between the isotope and the elemental ratios. Detailed analytical results are available from the authors upon request. Modeling of the argon data applied the algorithm and theories developed by Lovera et al. (1989, 1991) and led to kinetic parameters of argon loss and the cooling histories (see Eide et al., 1999). In the following, we use the word "domains" to describe the reservoirs from which argon was lost, as well as to reference their relative sizes which, in turn, describe their varying abilities to lose argon. Although this constitutes a first-order description that does not relate at first sight to physical objects in the lattice, our conclusions shed light on the physical existence and nature of these entities.

\section{Results and argon loss modeling}

In each of the three samples, the first striking features are the age spectra which exhibit strong age gradients. Otherwise, the K/Ca ratios in all of the samples are extremely high and in fact, very low Ca-derived ${ }^{37} \mathrm{Ar}$ values 
precluded the calculation of meaningful ratios. On the contrary, some $\mathrm{Cl}$ is present in the samples as demonstrated by the ${ }^{38}$ Ar contents (described below).

In the unbrecciated sample, ages climb from 100 Ma to an initial, semi-plateau at ca. 300 Ma, before abruptly climbing to a final plateau at ca. $390 \mathrm{Ma}$ in the highest temperature steps (Fig. 3a). The shape of the spectrum is most probably associated with the diffusion domain structure of the sample, together with a complex thermal history. Some $\mathrm{Cl}$ in the sample is evident in the degassing signatures at very low temperatures; this Cl-content then rapidly decreases (to very low ${ }^{38} \mathrm{Ar} /{ }^{39} \mathrm{Ar}$ ratios), suggesting that $\mathrm{Cl}$ is only present in fluid inclusions that explode below $600^{\circ} \mathrm{C}$. For the modeling, a unique activation energy (E) was used, in accordance with the statistical study of Lovera et al. (1997). The $\operatorname{logr} / \mathrm{r}_{\mathrm{o}}$ plot for this sample is successfully modeled with 5 domains with $\mathrm{E}$ of $46.6 \mathrm{kcal} / \mathrm{mol}$ (Fig. 4a); the latter value agrees with most estimates for activation energies for argon loss in alkali feldspars. The domain sizes and gas content distributions show that argon loss in the sample was dominated by two "large" domains containing more than $90 \%$ of the total gas. The two large domains correspond essentially to the single large (high temperature) domain modeled in these feldspars in the study by Eide et al. (1999).

To appreciate the relative sizes of the domains, the maximum in the $\operatorname{logr} / \mathrm{r}_{\mathrm{o}}$ plot is useful since it is, by definition (Lovera et al., 1989), a direct representation of the difference between the largest and smallest domains sizes. In the unbrecciated sample, the maximum $\log r / \mathrm{r}_{\mathrm{o}}$ value is 1.84 , notably also fairly typical for feldspars from crystalline basement rocks (Lovera et al., 1997). This sample is representative of the shape and derived cooling history obtained from all of the undeformed feldspars previously analysed and modeled in the Sunnfjord area (see above and Eide et al., 1999).

The slightly brecciated sample (95AS3), physically closer to the fault breccia, yields an age spectrum pattern very similar to the unbrecciated sample: the steps rise from ca 100 Ma up to an initial, semi-plateau at 300 Ma, before reaching a final plateau at ca. $390 \mathrm{Ma}$. Again, some $\mathrm{Cl}$ is apparently degassed at low temperatures, while the $\mathrm{K} / \mathrm{Ca}$ ratios remain high throughout the experiment (Fig. 3b). Although five classes of domain sizes with a constant E of 46.6 $\mathrm{kcal} / \mathrm{mol}$, indistinguishable within error from parameters obtained from the undeformed sample, are sufficient to model diffusion in this sample, the details of the modeled diffusion behaviour in the slightly brecciated sample elucidate a slightly different domain distribution compared to the unbrecciated feldspar. On the $\operatorname{logr} / \mathrm{r}_{\mathrm{o}}$ plot, this is evident first, through the maximum $\operatorname{logr} / \mathrm{r}_{\mathrm{o}}$ value of 2 (slightly higher than that of the unbrecciated sample) (Fig. 4b), and second, via the subtle variation in the slope of the $\operatorname{logr} / \mathrm{r}_{0}$ graph between 0 and $30 \%$ of the degassed ${ }^{39} \mathrm{Ar}$ (the slope is shallower than that in the unbrecciated sample; compare Figures 4a and b where the "plateau" at $1.2 \pm 0.1$ is obtained at ca. $17 \%$ for the undeformed sample and after $24 \%$ for the slightly brecciated one). These two differences in the logr $/ \mathrm{r}_{0}$ behavior are indicative of an increase in minimum versus maximum domain sizes, as well as of the total amount of gas released by 
the "smallest" domains: up to $22 \%$ of ${ }^{39} \mathrm{Ar}$ is now apparently contained in small domains in this slightly deformed sample, compared to less than $10 \%$ of ${ }^{39} \mathrm{Ar}$ in "small” domains in the unbrecciated case.

In the brecciated sample, we observe a dramatic re-enforcement of the behavior outlined above, in addition to some new features. The age spectrum has a very different shape compared to both of the other samples: the steps rise slowly from almost 0 age to a very irregular, semi-plateau around 300-350 Ma and at the end of the experiment, the highest temperature steps exhibit a distinct and rapid decrease in apparent ages (down to ca $150 \mathrm{Ma}$ ). The amount of $\mathrm{Cl}$ degassed at low temperatures is higher than that observed in the other two samples and, probably more importantly, some $\mathrm{Cl}$ is also released in the higher temperature steps, corresponding to the age maxima in the spectrum. This behaviour implies $\mathrm{Cl}$ in two different reservoirs in this sample (Fig. 3c), as was also proposed by detailed studies of the location of excess argon (Harrison et al., 1994; Foster et al., 1990). It is noteworthy that for the same temperature steps, no correspondingly significant change is observed in the K/Ca ratios of the sample. For diffusion modeling, at least 8 domains with constant $\mathrm{E}$ of $44.8 \mathrm{kcal} / \mathrm{mol}$ replicate the $\log r / \mathrm{r}_{\mathrm{o}}$ plot adequately. While this number of domains used in the modeling is the highest amongst the three samples, the activation energy for this sample is identical within statistical and numerical errors of those obtained from the other two samples. Upon closer examination of the logr $/ \mathrm{r}_{\mathrm{o}}$ plot for the brecciated sample, we see a much shallower slope of the line through the initial set of data compared the other two samples. The $\log r / \mathrm{r}_{\mathrm{o}}$ value then increases very slightly over the course of the experiment to a maximum value of 2.5 after more than $85 \%$ of the ${ }^{39} \mathrm{Ar}$ has been lost; this value is clearly the highest of the three samples studied (Fig. 4c). In terms of domain sizes, the larger number of domains and their behaviour in the brecciated samples as represented by the $\log r / r_{0}$ diagram indicate domains with size contrasts greater than those found in the previous two, less deformed samples; in this case, the first 7 of the 8 domains contain $86 \%$ of all ${ }^{39} \mathrm{Ar}$ liberated during the experiment and also have the 'smallest' sizes (compare to Figures 4a and b). We note that the inverse isochron plot for the brecciated sample also exhibits the highest amount of air contamination of the three samples studied. Introduction of air is most simply explained by atmospheric pollution on newly created crystal surfaces at the earth surface or during sample preparation as discussed below.

\section{EVOLUTION OF BRECCIATION AND ARGON LOSS}

A broad assessment of the data and the modeled results indicates a clear relation within and between each sample in terms of: 1) their chronologic memories, 2) the kinetics and magnitude of argon loss and 3) their degrees of brecciation. Utilising the undeformed sample as a baseline, progressive breccia-related deformation (from the undeformed to the slightly deformed samples) is manifested by an increase in the amount of gas released from the smallest domains in the feldspars. However, comparison between the maximum values in the logr/ $\mathrm{r}_{0}$ plots of the 
undeformed versus the slightly deformed sample does not reveal a significant increase in gas released from one sample compared to the other over the same experimental ranges. We note that MDD modeling does not allow us to distinguish the real size ranges, but rather just the ratios between biggest and smallest domains. From this discussion, one could argue that the true size of the biggest and smallest domain has changed from the undeformed to the slightly deformed sample. However, we suggest instead that, since feldspars are chemically identical along section and belong to the same host rock, the simplest explanation is that the overall intersample size differences between small and large domains have not changed (increased) significantly as a result of mild brecciation. Rather,initial brecciation (passing from undeformed to slightly deformed feldspars) brought about a situation whereby more lattice sites containing argon were included in small domains. This explanation would facilitate the apparent increase in gas release from the smallest domains without requiring that the true size of the domains has changed between the two samples. Put simply, the data indicate that the volume of the grain enclosed in small domains and/or the number of small domains have increased with mild brecciation. While the migration of argon from bigger to smaller domains would affect a similar behaviour, we findsuch an explanation to be thermodynamically improbable. Since large amounts of argon were not lost from the sample (compare, for example, their release spectra in Fig. 3), argon diffusion out of the feldspar was probably restricted. Any minor argon diffusion out of the slightly brecciated feldspar, when compared to feldspars physically farther from the brittle fault, is associated with local fracturing of the feldspar grains and transport of weakly bound Ar away from the feldspars by intergranular fluids (Eide et al. 1999).

The progression of the effects of brecciation is evident when we incorporate the most deformed sample in the comparison; this sample reveals a strikingly larger volume of ${ }^{39} \mathrm{Ar}$ gas released from small domains than that released in the other two samples. Moreover, the $\log r / r_{0}$ maximum in the brecciated sample shows that the ratio of size from biggest to smallest domains has increased during brecciation. Again, we have no direct measure of domain sizes and both the size of smallest and biggest domains may have changed. However, although an increase in domain size of the biggest domains during brecciation is theoretically possible, a decrease in size as a result of mechanical grinding is, of course, a more logical outcome. At this stage it is difficult to say whether only the smallest domains were reduced in size or if both biggest and smallest domains were ground to finer dimensions; if the latter is correct, the smallest domains in the brecciated sample would, by implication, have even smaller dimensions than those in the slightly brecciated sample since the $\log r / \mathrm{r}_{\mathrm{o}}$ shows an increase. Argon loss has clearly been enhanced in this sample, but it does not appear that the 'lost' argon was simply redistributed within the grains since every part of the age spectrum has a lower apparent age than comparable parts of the spectra from the other two samples. Similarly, whole rock, step-heating analysis of the green breccia (host rock of the brecciated feldspar) likewise does not show excess argon (see Eide et al., 1997), thus implying that argon was lost wholescale from the rock system itself and not only from the feldspar grains. This fairly pervasive 'flushing' of argon from the system is most readily related to enhanced fluid flux during formation 
of the green breccia; greater fluid flux has previously been documented by crystallisation of hydrous, low-grade metamorphic minerals, by development of fluid-related chemical remanent magnetic signature (ChRM) (Torsvik et al., 1992; Eide et al., 1997) and also by the higher Cl content exhibited by this sample, even within the 'deeper' (higher temperature) parts of the grain. The end of the age spectrum for the brecciated sample also shows marked argon loss which at this time we find difficult to explain either kinetically or physically.

\section{Physics of DEFormation, ARgon Loss AND Domains}

We emphasize the fact that domain analyses have been conducted, as is usually the case, solely on the loss of

${ }^{39} \mathrm{Ar}$ in laboratory. Thus, the question remains: what is the relation, if any, between the "domain" structure identified in the laboratory and the actual behavior of the sample in nature? This has obvious consequences on the assessment of the existence and behaviour of domains in nature. Existence and potential use of domains have been particularly challenged in the recent work of Parsons et al. (1999) and, following their thoughtful analysis our own work, can help to bring elements of answers to the following questions:

\section{Did domains exist prior to treatment in the laboratory?}

To answer this question, we would have to test the idea that thepeculiar degasing we observe was a direct product of the separation, crushing, sieving, irradiation and step heating of the samples. A simple experiment would be to compare the thermal history of undeformed and deformed samples subsequent to brecciation to see if the age record (thus a direct measure of ${ }^{40} \mathrm{Ar}$ kinetics) agrees with the behaviour obtained from the loss of ${ }^{39} \mathrm{Ar}$. An agreement would be a strong incentive to propose that what we see as a result of laboratory experiment and modeling did exist in nature, prior to laboratory analysis. Unfortunately, our samples did not record any meaningful cooling information after brecciation since this last event occurred around $250^{\circ} \mathrm{C}$ and ended well below K-feldspar closure temperature. Geological targets that fulfill all requirements to perform this test (e.g. homogeneous petrography in undeformed and deformed rocks, low temperature brittle deformation, significant thermal history after brecciation) are difficult to find. We note the urgent need for such studies. The inability to carry out this sort of test leads us to acknowledge fully that all

${ }^{39} \mathrm{Ar}$ loss in our samples could be due to complex structural changes in the samples during laboratory treatment. Nonetheless, the fact that all undeformed feldspars share very common diffusion behavior (Eide et al., 1999), while slightly to highly deformed onesshow altered diffusional characteristics suggest strongly that the laboratory revelations have some basis in real structures acquired in nature. Moreover, argon loss in nature, as evidenced by the age variations, is qualitatively comparable to the alteration of the ${ }^{39} \mathrm{Ar}$ loss. 
Many lines of research have been devoted to the description of textural changes during feldspar cooling. The complexity of sub-solidus changes has been especially emphasised as proof that these textural changes occurred below the temperatures claimed to be recovered by MDD. In our case, domain modification clearly happened below the average closure temperature for argon loss in K-feldspars. Moreover, if laboratory artefacts are discarded, we can conclude that the peculiar diffusion behavior developed because of brecciation--either because brecciation dictated the development of post-deformation diffusion structures, or because brecciation created new domains. These samples exhibit a remarkable coincidence between structural and textural evolution as observed microscopically and via argon diffusion. Clearly in these experiments, the domains in the deformed samples are intuitively associated with subgrain structures of which some are petrographically visible. Indeed, subgrains develop during deformation by the development of physical breaks of the lattice; these breaks can be caused by defect migration that in turn, leads to evolution of undeformed pieces of lattice surrounded by coherent boundaries. Such isolated structures will behave as completely independent grains, sharing all the diffusion characteristics suggested for diffusion domains by Harrison, Lovera and co-workers: the small grains or domains are not nested, they have a typical size distribution, and diffusion in each of those domains is volumetric. This is an extreme case in which the existence of domains is not an intrinsic characteristic of the original feldspars but rather is an effect of deformation.

\section{Did domains exist prior to brecciation?}

One can also infer the existence of domains with the above characteritics prior to deformation: the most retentive and thus "largest” structures identified in the unbrecciated sample seem to decrease in size during brecciation. They are in this way physical entities that we define as volumetric areas limited by coherent boundaries; probably, these 'entitites' are the grains themselves. We find no other plausible definition of these data that would allow the domains to be partitioned during brecciation. The physical existence of the smallest domains is more difficult to prove but they apparently can also be affected by grain size reduction, and therefore must exist physically in the lattice. The fact that the slightly brecciated sample shows more small domains of roughly the same sizes as the smallest domains from the unbrecciated sample is more puzzling, since there is no logical reason for which newly formed domain-like subgrains would have the same size as inherited intrinsic domains in the feldspars. We can offer only that perhaps the size distribution of intrinsic domain structures in feldspars and developing subgrains at the lattice scale are promoted for certain typical sizes.

\section{A plausible scenario}

If we attempt to relate the argon diffusion and domain evolution with the physical process of brecciation, a simple model of crack propagation would satisfactorily explain the observed behaviour. We propose a model where, 
during the early stage of brecciation, crack propagation in the feldspars tended to cut randomly through the grains, individualizing new domains of intermediate, smaller, effective diffusion length (Fig. 5). Note that we utilise the partially brecciated sample here as a proxy for 'early' brecciation. Because temperatures were fairly low, brecciation itself did not significantly enhance diffusion, and the appearance of smaller domains in themselves did not translate into enormous argon loss; likewise, fluids in the 'early' brecciation phase were volumetrically small and did not enhance strain-related crack propagation or facilitate wholescale argon flushing. When we proceed in the laboratory to the completely brecciated sample, the grains behave as if composed of a higher density of smaller domains, which we interpret to represent in nature a very effective period of crack propagation during the peak stage of brecciation; this pervasive crack propagation would actively reduce the size of any pre-existing domains and individualize some of these domains to sizes even smaller than those in the lesser deformed samples. This would also induce a net increase in the surface over volume ratio of the grains and thus explain the highest atmospheric contamination in the brecciated grains simply by a higher adsorbed quantity of atmospheric argon, most probably during sample stay at the earth's surface. Argon loss would be enhanced at this advanced stage because of increased temperature, because of enhanced deformation within the locus of brecciation and/or because of increased fluid flow. At the same time that domain size reduction was enacted, argon also diffused globally out of all the domains (both 'original' and new domains). Some argon certainly diffused out of the grain via 'lattice volume-diffusion', but it is likely that most of argon loss was produced via volume diffusion first from the feldspar lattice to the new, neighbouring cracks, and then to the mineral surface, with the cracks acting as fast diffusion pathways. If the new, small domains were nested inside surviving (relict) big domains, we would not expect to 'see' them with this type of analysis (they would be effectively masked by the larger domains); that the small domains appear at all implies that they exist as entitites bound instead by fast diffusion pathways. Existence of fast diffusion pathways may also explain why the memory of the "biggest" domains, usually equated with 'greatest retentivity' at highest temperatures, seems to be selectively and categorically erased (witness the complete loss of the ca $390 \mathrm{Ma}$, Caledonian plateau), while the intermediate domains seem to retain their ages (са. 300 Ma). Although the true physical manifestation of this behaviour remains speculative, one straightforward possibility is that the biggest domains, if indeed they exist as spatial entities, are simply more likely to be intersected by any cracks generated in the grain. Because argon diffusion will be essentially controlled by rapid diffusion along these cracks, the big domains would lose their argon more rapidly and at an earlier stage than would the intermediate- or small-sized domains (Fig. 5). Interestingly, a high $\mathrm{Cl}$ content is associated with the age maxima of the spectrum for the brecciated sample, suggesting that loss by rapid diffusion along the crack network was enhanced by fluid flow. This $\mathrm{Cl}$ content is the highest recorded among the variably brecciated samples and it is interpreted as reflecting a stong fluid circulation along the cracks during brecciation climax. 
We freely note the difficulty in explaining the zero (0 Ma) ages at the beginning of the spectrum in the brecciated sample, as well as the decrease of the ages at the end of the spectrum. Null ages at the beginning of degassing have already been outlined in gem-quality feldspars (Arnaud and Kelley, 1997) and attributed to the opening of fractures intersecting the surface of the grain, probably during laboratory sample preparation (crushing). These fractures should contain argon lost from the lattice, not all of which was liberated from the grain, due to the fact that some of the fractures never intersected the grain surface until laboratory crushing. In our in naturo crushing sample, wholescale argon loss has nonetheless occurred from the bulk of the grain (and the rock) as shown by the low age maxima in the spectrum and the whole rock analysis of the breccia (Eide et al. 1997). In our example, it is conceivable that not all of the cracks were connected to the grain surfaces and thus accumulated argon that was subsequently liberated during sample preparation. One or both of these processes would lead to spurious 0 ages. Any explanation for the precipitous drop in ages at the high-temperature end of the spectrum only by means of domain size redistribution must somehow incorporate complete diffusion of the argon out of the high-temperature domains and subsequent redistribution of this argon partially into newer, smaller domains, which implies a very complex diffusion picture inside those grains. Alternatively, the drop in K/Ca ages at the end of the spectrum could evidence mixing between feldspar phases of different age but similar retentivities. New albitic feldspar grew inside the most brecciated grains under the influence of temperature and fluid flow. We note that these new phases are pristine and constitute retentive domains with lower ages since they form after the main brecciation event. Consequently, they could be expected to show their Ar signatures at high laboratory temperatures, at the same experimental temperatures where the big domains in the pristine K-feldspars were degasing.

\section{Conclusions}

The diffusion behaviour during brecciation as described herein highlights how complex and variable those processes can be: they strongly depend upon the rate of the process (both strain and recovery), the degree of fluid flow, the temperature and probably other variables not observed in this study. The significant constraint brought by our in naturo study is that deformation in rather dry and cold conditions does not induce argon loss on a large scale. The propagation of cracks, however, significantly affects the theoretical diffusion pattern of the crystals. Only when deformation climaxes and temperature and fluid flow have increased can one expect massive argon loss. At the maximum phase of brecciation, two processes compete: rapid, "open path" diffusion and lattice diffusion. The former is likely to be especially efficient when the density of cracks is so high that a completely connected network develops, inducing rapid loss even from the formerly big domains, that then selectively lose their argon memory. Any fluid flow will only serve to enhance that effect and will also flush argon out of the rock at the decimetre scale. Volume diffusion will develop only if temperature is sufficient, and will affect the structures according to their sizes. Therefore, in the 
absence of elevated temperatures or fluid flow we conclude that only extremely severe deformation is necessary to induce argon loss, which will subsequently proceed essentially via non-volume diffusion.

This study also has implications for the recovery of thermal histories from deformed alkali feldspars. First, weak or medium degrees of brittle deformation seriously alter the charateristics of argon diffusion, although significant argon loss is not induced. It follows that, although the memory of the grain has survived, the diffusion charateristics seen in the laboratory will be completely different from the ones that prevailed during the grain thermal history, prior to deformation. This is because the new domains are not intrinsic characteristics of the feldspars but are superimposed, acquired structures. Usually, this will transpose into anomalously low argon retentivities in abundant, low retentivity sites and would lead to an overestimation of cooling rates if modeled without care by MDD. This is likely to happen in old basement rocks in which multiple, low intensity events may lead to a seriously brecciated structure in feldspars that usually behave in a less ductile manner than other minerals. Second, argon loss during severe brecciation seems to be controlled initially by non-volume diffusion processes, characterized by loss along fast diffusion pathways intuitively associated with a denser and progressively connected network of cracks. In such rocks, modeling of temperature/duration variables using volume diffusion will of course be flawed and again, retentivity will be overestimated, leading to spurious temperatures or duration that are higher than reality.

Apart from suggesting that domains formed during deformation are physical subgrains, our study strongly supports the existence of the biggest domains as real physical entities visibly affected by brecciation Whether or not these domains are intrinsic characteristics of K-feldspars that can record cooling despite low-temperature alteration of the lattice is not accessible through our study. It must be stressed also that all diffusion behaviour highlighted in this study cannot, at present, be unequivocally distinguished from possible artefacts produced by laboratory treatment. However the agreement between geological microstructures, argon loss during brecciation and in the laboratory is rather suggestive of non-random artefacts. This study shows the amount of information one can extract from in naturo crushing studies. In vacuo crushing studies are highly valuable but are generally restricted to the study of finite products, and thus miss the evolution of the processes during deformation. In simple cases (for example, homogeneous feldspar compositions covering a wide range of degrees of deformation) in which the strain can be deduced and analysed both in terms of duration, strength and recovery, one can unravel the dynamic evolution deformation and related argon loss processes. This type of study clearly works only in areas with well-established geologic control to evaluate feldspar thermochronologic histories in terms of both the chronology and style of deformation. The obvious next step is to add a significant thermal overprint to this story to assess the existence of domains controlling argon diffusion in nature. 


\section{BIBLIOGRAPHY}

Albarède, F., G. Féraud, I. Kaneoka and E. C. J. Allègre (1978). “ 39Ar/40Ar dating: the importance of K-feldspars on multi-mineral data of polyorogenic areas. J. of Geology, 86, 581-598.

Andersen T. B., and Jamtveit B. (1990) Uplift of deep crust during orogenic extensional collapse: a model based on field studies in the Sogn-Sunnfjord region of Western Norway. Tectonics 9, 1097-1111.

Andersen T. B., Berry IV H. N., Lux D. R., and Andresen A. (1998) The tectonic significance of pre-Scandian ${ }^{40} \mathrm{Ar} /{ }^{39} \mathrm{Ar}$ phengite cooling ages in the Caledonides of Western Norway. J. Geol. Soc. London 155, 297-310.

Arnaud N. O., and Kelley S. (1997) Argon behaviour in gem-quality orthoclase from Madagascar: Experiments and some consequences for ${ }^{40} \mathrm{Ar} /{ }^{39} \mathrm{Ar}$ geochronology. Geochim. Cosmochim. Acta 61, 3227-3255.

Arnaud N. O., Brunel M., Cantagrel J. M., and Tapponnier, (1993) High cooling and denudation rates at Kongur Shan, eastern Pamir (Xinjiang, China) revealed by ${ }^{40} \mathrm{Ar} /{ }^{39} \mathrm{Ar}$ alkali feldspar thermochronology. Tectonics 12, $1335-1346$.

Brekke H., and Solberg O. (1987) The geology of Atløy, Sunnfjord, western Norway. Norsk Geol. Unders. Bull. 410, 73-94.

Dodson, M. H. (1973) Closure temperature in cooling geochronological and petrological systems. Contributions to Mineralogy and Petrology, 40, 259-274.

Dunlap W. J., and Fossen H. (1998) Early Paleozoic orogenic collapse, tectonic stability, and late Paleozoic continental rifting revealed through thermochronology of K-feldspars, southern Norway. Tectonics 17, 604-620.

Eide E. A., Torsvik T. H., and Andersen, T. B. (1997) Absolute dating of brittle fault movements: Late Permian and late Jurassic extensional fault breccias in western Norway. Terra Nova 9, 135-139.

Eide E. A., Torsvik T. H., Andersen T. B and Arnaud, N. O. (1999) Early Carboniferous unroofing in western Norway: A tale of alkali feldspar thermochronology. J. Geol. (in press).

Færseth R. B., Macintyre R. M., and Naterstad J. (1976) Mesozoic alkaline dykes in the Sunnhordaland region, western Norway: ages, geochemistry and regional significance. Lithos 9, 331-345.

Færseth, R. B. (1996) Interaction of Permo-Triassic and Jurassic extensional fault-blocks during the development of the northern North Sea. J. Geol. Soc. Lond. 153, 931-944.

Fitzgerald J. D. and Harrison T. M. (1993) Argon diffusion domains in K-feldspars I: microstructures in MH-10. Contrib. Mineral. Petrol. 113(3), 367-380

Fossen H., and Dunlap W. J. (1998) Timing and kinematics of Caledonian thrusting and extensional collapse, southern Norway: evidence from ${ }^{40} \mathrm{Ar} /{ }^{39} \mathrm{Ar}$ thermochronology. J. Struct. Geol. 20, 765-781.

Harrison T.M., Lovera O.M., and Heizler M.T. (1991) ${ }^{40} \mathrm{Ar} /{ }^{39} \mathrm{Ar}$ results for alkali feldpsars containing diffusion domains with differing activation energy. Geochim. Cosmochim. Acta 55, 1435-1448. 
Harrison, T. M. (1990) Some observations on the interpretation of feldspar ${ }^{40} \mathrm{Ar} /{ }^{39} \mathrm{Ar}$ results. Chemical Geology, Isotope geoscience section $\mathbf{8 0}, 219-229$.

Harrison, T.M., Heizler M. T., Lovera O. M., Wenji C. and Grove M. (1994) A chlorine disinfectant for excess argon released from K-feldspar during step heating. Earth Planet. Sci. Lett. 123, 95-104.

Harrison, T.M., Heizler M.T., and O. M. Lovera (1993) In vacuo crushing experiments and K-feldspar thermochronometry. Earth and planetary science letters 117, 169-180.

Leloup H., Lacassin R., Tapponnier P., Schärer U., Dalai Z., Xiaohan L., Liangshang Z., Shaocheng J. and Trinh Tong (1995) The Ailao Shan-Red River shear zone (Yunnan, China), Tertiary transform boundary of Indochina. Tectonophysics 251, 3-84.

Lovera, O. M., Richter F.M., and Harrison T.M. (1991) Diffusion domains determined by ${ }^{39}$ Ar released during step heating. J. Geophys. Res. 96, 2057-2069.

Lovera, O.M., Grove M., Harrison T.M., (1993) Argon diffusion domains in K-feldspars II: kinetic properties of MH10. Contrib. Mineral. Petrol. 113, 381-393.

Lovera, O.M., Grove M., Harrison T.M., and Mahon K. I. (1997) Systematic analysis of K-feldspar ${ }^{40} \mathrm{Ar} /{ }^{39} \mathrm{Ar}$ step heating results: I. Significance of activation energy determinations. Geochim. Cosmochim. Acta 61, 3171-3192.

Lovera, O.M., Richter F.M., and Harrison T.M. (1989) The ${ }^{40} \mathrm{Ar} /{ }^{39} \mathrm{Ar}$ thermochronometry for slowly cooled samples having a distribution of diffusion domain sizes. J. Geophys. Res. 94, 17917-17935.

Maluski H., and Schaeffer O. A. (1982) ${ }^{39} \mathrm{Ar}-{ }^{40} \mathrm{Ar}$ laser probe dating of terrestrial rocks. Earth Planet. Sci. Lett. 59, 2127.

Osmundsen T., Andersen T. B., Markussen S., and Svendby A. K. (1998) Tectonics and sedimentation in the hanging wall of a major extensional detachment: The Devonian Kvamshesten Basin, western Norway. Basin Res. 10, 213234.

Parsons I., Waldron K.A., Walker F.D.L., Burgess R., and Kelley S. (1991) Microstructural controls of ${ }^{40}$ Ar loss and ${ }^{18} \mathrm{O}$ exchange in alkali feldspars. EOS, Trans. AGU 72, 290.

Parsons, I., W. Brown, L., and J. Smith, V. (1999) 40Ar/39Ar thermochronology using alkaly feldspars: real thermal history or mathematical mirage of microtecture ?. Contribtions to Mineralogy and Petrology, 136, 92-110.

Reddy S. M., Potts G. J., Kelley S., and Arnaud N. O. (1998) The effects of deformation-induced microstructures on intragrain argon isotope ages. Geology, (in press27), 363-366.

Torsvik T. H., Andersen T. B., Eide, E. A., and Walderhaug H. (1997) The age and tectonic significance of dolerite dykes in western Norway. J. Geol. Soc. Lond. 154, 961-973. 
Torsvik T. H., Sturt B. A., Swensson E., Andersen T. B., and Dewey J. F. (1992) Palaeomagnetic dating of fault rocks: evidence for Permian and Mesozoic movements and brittle deformation along the extensional Dalsfjord Fault, western Norway. Geophys. J. Int. 109, 565-580.

Tullis J. and Yund R.A. (1991) Experimental evidence for diffusion creep in feldspar aggregates. J. Struc. geol. 13, $987-1000$.

Tullis, J. and Yund R.A. (1996) Deformation-enhanced fluid distribution in feldpar aggregates and implications for ductile shear zones. Geology 24, 63-66.

Villa, I. M. (1994) Multipath Ar transport in K-feldspar deduced from isothermal heating experiments. Earth Planet. Sci. Lett. 122, 393-401.

Zeitler, P. K. (1987) Argon diffusion in partially outgassed alkali feldspars: insights from 40Ar/39Ar analysis Chemical Geology, Geol. Isot. Geosc Sec. 65, 167-181.

\section{CAPTIONS}

\section{Table 1.}

Results of step heating degassing. The first table gives isotopic data errors and ages with the quantity of ${ }^{39} \mathrm{Ar}$ released (moles) and cumulative $\%{ }^{39} \mathrm{Ar}$. The second table shows diffusion parameters calculated during experimental heating. Values are shown as “ 0.000 ” when the mass spectrometer signals were below blank levels.

\section{Table 2.}

Input parameters for diffusion modeling of the $\log \left(\mathrm{r} / \mathrm{r}_{\mathrm{o}}\right)$ plots.

\section{Figure 1.}

Location map, of the studies samples, together with a simplified chronostratigraphy and reported ages. Numbers on the stratigraphic column refer to references in bibliography.

\section{Figure 2a-d.}

Photomicrographs showing basic grain-scale evolution of brittle deformation in these rocks from 'unbrecciated' through to the breccia with special focus on the K-feldspars. Scale bars are shown in each photograph. 
A/ unbrecciated sample (95AS1) with coarse-grained perthitic microcline with interlocking texture, containing albite lamellae or blebs; rims of alkali feldspars are free of lamellae and inclusions and may be slightly more Na-rich. Fine-scale features reveals some irregular to serrated grain boundaries, minor undulatory extinction, minor subgrain development at alkali feldspar rims, strained twins in plagioclase, and polygonal quartz rinds around some alkalifeldspar porphyroblasts

B/ slightly brecciated sample (95AS2) with microperthitic alkali feldspar containing deformed albite lamellae. Grain boundaries are serrated and subgrain growth is both more developed and irregularly distributed at grain boundaries as well as in the interiors of grains. Undulatory extinction is common and is not affected by subgrain limits. Brittle deformation is manifested as fractures/cracks that crosscut individual porphyroblasts and/or that visibly offset portions of single grains and stair-step fractures are also evident.

C and D/ two fields in the highly brecciated sample (95AS4B). The cataclastic activity facilitated propagation of fractures through weakened grains which subsequently induced a significant amount of autocataclasis. Angular alkali feldspar clasts are surrounded by anastomosing veinlets comprising fine, feldspar fragments, chlorite, epidote, titanite, magnetite and fine-grained, layer silicates. The angular feldspars themselves are composed almost exclusively of weakly visible, large, sub-grains with preserved perthitic feldspar cores containing deformed or ‘wormy’ albite lamellae. In some relict grains, the typical ‘crosshatch’ twinning of the microclines appears skewed. Occurrence of new, replacement minerals like quartz and albite on and in the alkali feldspars is evident, especially near areas of pronounced grain reduction. Finer-grained, disaggregated feldspar fragments float in the greenschistfacies 'matrix'.

\section{Figure 3.}

Similar heating schedules applied to the three samples.

\section{Figure 4abc.}

Age and diffusion information for each sample. Age spectra are shown (top darwing) together with $\log \left(\mathrm{r} / \mathrm{r}_{\mathrm{o}}\right)$ plots (bottom drawing) on which diffusion model has been reported (thicker line). because model almost perfectly fit the intial $\log \left(\mathrm{r} / \mathrm{r}_{0}\right)$ values they are almost indistinguishable. The change in diffusion characteristics from one sample to another is shown by the comparison of the relative domain sizes (obtained from $\log \mathrm{D}_{\mathrm{o}} / \mathrm{r}^{2}$ and compared to the highest retentivity domain) and relative volume fractions (the relative fraction of ${ }^{39} \mathrm{Ar}$ contained in the degassed sites). The most spectacular effect is the increasing importance of the small domains, progressively decreasing in size and becoming more numerous.

\section{Figure 5abc.}


${ }^{39} \mathrm{Ar} /{ }^{37} \mathrm{Ar}$ (thick line) and ${ }^{38} \mathrm{Ar} /{ }^{39} \mathrm{Ar}$ (thin line) used as proxies for $\mathrm{K} / \mathrm{Ca}$ and $\mathrm{Cl} / \mathrm{K}$ correlation plots. Note that the most deformed sample shows a very different degassing pattern than the two others, suggesting a lower $\mathrm{K} / \mathrm{Ca}$ and $\mathrm{Cl}$ rich phase now dominates the highest temperature steps of the degassing.

\section{Figure 6.}

Inverse isochron diagram underscoring the increasing amount of non radiogenic argon in the most deformed sample, probably due to an increase surface to volume ratio associated to brecciation..

\section{Figure 7.}

Highly simplified sketch scenario of the relations between physical deformation processes and diffusion of argon in naturo, both in terms of residing sites and diffusion processes, with emphasis on the K-feldspar (Ksp). Argon (black lettering) is shown as ArK when produced in situ from K, and Ar, when inherited at the time of, or after, feldspars formation.

A/ typical situation in an undeformed sample fater Devonian and prior to Permian faulting. the sample is composed of Ksp, plagioclase (Pl), quartz (Qz) and late groundmass interstitial minerals (GS minerals). Ksp have an originally complex structure which is interpreted as forming domains of diffusion (see text for a detailed discussion of this assumption) which are voluntarily grossly sketched since their real nature is unknown.. The sample being below closure temperature, argon is not lost from the sample except maybe on the its very borders (black arrows).

B/ brecciation starts at low temperature. Crushed zones appear firstly between grains, along with quartz dynamic recrystallization and new Ksp (Ksp2) crystallization. Fractures propagate into more coherent grains such as Ksp and individualize newly formed "small" domains, trapping argon (white lettering) already present or in-situ decayproduced after crack propagation. No diffusion yet develops although those cracks form proto-fast diffusion pathways which will be activated later.

$\mathrm{C} /$ brecciation proceeds and produces cataclasite formation. Inside Ksp grains fracturing is intense, along with the formation of new albitic pristine feldspar. numerous "small" newly-formed domains contain most of argon, either ineherited or in-situ produced. Diffusion is enhanced by fluid-flow and argon (white lettering and boxed) diffuses using fast diffusion pathways (white arrows) as soon as it exits from a small domain using volume diffusion (black arrows). not that argon from the albitic crystals probably does not diffuse out. 


\begin{tabular}{|c|c|c|c|c|c|c|c|c|c|c|}
\hline $\begin{array}{l}\text { Temp } \\
{ }^{\circ} \mathrm{C}\end{array}$ & ${ }^{40} \mathrm{Ar} /{ }^{39} \mathrm{Ar}$ & ${ }^{38} \mathrm{Ar} /{ }^{39} \mathrm{Ar}$ & ${ }^{37} \mathrm{Ar} /{ }^{39} \mathrm{Ar}$ & $\begin{array}{c}{ }^{36} \mathrm{Ar}{ }^{39} \mathrm{Ar} \\
\left(10^{-3}\right)\end{array}$ & $\begin{array}{c}{ }^{39} \mathrm{Ar} \\
\left(10^{-14} \mathrm{moles}\right)\end{array}$ & $\begin{array}{l}\mathrm{F}^{39} \mathrm{Ar} \\
\text { released }\end{array}$ & $\%{ }^{40} \mathrm{Ar} *$ & ${ }^{40} \mathrm{Ar} * /{ }^{39} \mathrm{Ar}$ & $\begin{array}{l}\text { Age } \\
\text { Ma }\end{array}$ & $\begin{array}{l} \pm 1 \sigma \\
\mathrm{Ma}\end{array}$ \\
\hline 95 As 1 & & K-feldspar & & $\mathrm{J}=0.0068510$ & & $\mathrm{wt}=4 \mathrm{mg}$ & & & & \\
\hline 400 & 18.094 & 0.050 & 0.002 & 33.082 & 0.06 & 0.19 & 46.77 & 8.46 & 101.68 & 4.09 \\
\hline 400 & 17.351 & 0.031 & 0.000 & 10.803 & 0.07 & 0.43 & 81.73 & 14.18 & 167.27 & 5.18 \\
\hline 450 & 19.466 & 0.030 & 0.001 & 8.560 & 0.08 & 0.67 & 87.06 & 16.95 & 198.16 & 4.68 \\
\hline 500 & 22.106 & 0.026 & 0.011 & 4.852 & 0.54 & 2.42 & 93.47 & 20.66 & 238.86 & 4.49 \\
\hline 500 & 23.774 & 0.023 & 0.003 & 2.297 & 0.22 & 3.12 & 97.04 & 23.07 & 264.74 & 11.57 \\
\hline 550 & 25.789 & 0.023 & 0.004 & 1.504 & 0.31 & 4.14 & 98.17 & 25.32 & 288.54 & 10.63 \\
\hline 550 & 26.831 & 0.021 & 0.007 & 0.842 & 0.33 & 5.20 & 98.95 & 26.55 & 301.49 & 5.85 \\
\hline 600 & 27.473 & 0.023 & 0.012 & 1.201 & 0.43 & 6.59 & 98.60 & 27.09 & 307.12 & 13.12 \\
\hline 600 & 27.291 & 0.022 & 0.006 & 0.446 & 0.27 & 7.45 & 99.39 & 27.13 & 307.50 & 11.31 \\
\hline 650 & 28.126 & 0.022 & 0.001 & 1.198 & 0.41 & 8.79 & 98.63 & 27.74 & 313.91 & 11.29 \\
\hline 650 & 27.548 & 0.021 & 0.000 & 0.225 & 0.25 & 9.60 & 99.63 & 27.45 & 310.83 & 10.96 \\
\hline 700 & 27.932 & 0.022 & 0.001 & 1.172 & 0.40 & 10.89 & 98.65 & 27.55 & 311.97 & 12.83 \\
\hline 700 & 27.823 & 0.022 & 0.004 & 0.363 & 0.24 & 11.66 & 99.49 & 27.68 & 313.28 & 11.77 \\
\hline 750 & 28.331 & 0.022 & 0.001 & 0.701 & 0.35 & 12.79 & 99.15 & 28.09 & 317.53 & 10.81 \\
\hline 750 & 28.469 & 0.021 & 0.000 & 0.399 & 0.27 & 13.67 & 99.46 & 28.32 & 319.87 & 10.45 \\
\hline 800 & 28.757 & 0.022 & 0.001 & 1.199 & 0.34 & 14.77 & 98.66 & 28.37 & 320.45 & 12.40 \\
\hline 800 & 28.963 & 0.022 & 0.000 & 0.888 & 0.27 & 15.63 & 98.98 & 28.67 & 323.51 & 12.18 \\
\hline 800 & 29.088 & 0.022 & 0.000 & 0.364 & 0.21 & 16.31 & 99.51 & 28.94 & 326.37 & 13.30 \\
\hline 800 & 28.983 & 0.022 & 0.000 & 0.000 & 0.36 & 17.49 & 99.87 & 28.95 & 326.37 & 11.88 \\
\hline 700 & 42.275 & 0.023 & 0.000 & 31.739 & 0.01 & 17.52 & 78.14 & 33.03 & 368.05 & 37.71 \\
\hline 750 & 31.876 & 0.019 & 0.000 & 0.547 & 0.02 & 17.60 & 99.39 & 31.68 & 354.36 & 17.70 \\
\hline 800 & 30.188 & 0.022 & 0.000 & 0.000 & 0.07 & 17.82 & 99.88 & 30.15 & 338.77 & 6.75 \\
\hline 850 & 29.671 & 0.023 & 0.000 & 0.794 & 0.20 & 18.46 & 99.10 & 29.40 & 331.09 & 18.41 \\
\hline 900 & 29.884 & 0.023 & 0.001 & 1.501 & 0.42 & 19.83 & 98.42 & 29.41 & 331.17 & 17.71 \\
\hline 950 & 30.366 & 0.024 & 0.001 & 1.920 & 0.73 & 22.20 & 98.04 & 29.77 & 334.88 & 19.22 \\
\hline 1000 & 31.322 & 0.025 & 0.001 & 2.272 & 1.36 & 26.59 & 97.78 & 30.63 & 343.62 & 20.05 \\
\hline 1050 & 32.740 & 0.025 & 0.001 & 2.281 & 2.65 & 35.18 & 97.87 & 32.04 & 358.03 & 18.43 \\
\hline 1150 & 35.842 & 0.027 & 0.001 & 2.613 & 5.15 & 51.86 & 97.78 & 35.05 & 388.23 & 32.54 \\
\hline 1200 & 36.210 & 0.027 & 0.000 & 2.222 & 8.31 & 78.78 & 98.12 & 35.53 & 393.02 & 28.10 \\
\hline 1400 & 36.750 & 0.027 & 0.000 & 2.298 & 6.55 & 100.00 & 98.09 & 36.05 & 398.16 & 30.32 \\
\hline
\end{tabular}

\begin{tabular}{|c|c|c|c|c|c|c|}
\hline $\begin{array}{c}\text { Temp } \\
{ }^{\circ} \mathrm{C}\end{array}$ & $\begin{array}{l}\text { Time } \\
\text { min }\end{array}$ & $\mathrm{f}$ & $\mathrm{D} / \mathrm{r}^{2}$ & $\begin{array}{c}1000 / \mathrm{T} \\
\left(\mathrm{K}^{-1}\right)\end{array}$ & $-\log \left(\mathrm{D} / \mathrm{r}^{2}\right)$ & $\log \left(r / r_{0}\right)$ \\
\hline \multicolumn{7}{|c|}{$\mathrm{E}=38696 \mathrm{cal} / \mathrm{mol}+-4973 \log (\mathrm{Do} / \mathrm{ro})=4.14 / \mathrm{s}+-1.48$} \\
\hline 400 & 20 & 0.19 & 2.33E-09 & 1.486 & 8.633 & 0.106 \\
\hline 400 & 30 & 0.43 & $6.46 \mathrm{E}-09$ & 1.486 & 8.190 & -0.116 \\
\hline 450 & 20 & 0.67 & $1.76 \mathrm{E}-08$ & 1.383 & 7.756 & 0.102 \\
\hline 500 & 20 & 2.42 & 3.53E-07 & 1.294 & 6.452 & -0.172 \\
\hline 500 & 30 & 3.12 & 1.69E-07 & 1.294 & 6.771 & -0.013 \\
\hline 550 & 20 & 4.14 & 4.83E-07 & 1.215 & 6.316 & 0.092 \\
\hline 550 & 30 & 5.20 & 4.33E-07 & 1.215 & 6.363 & 0.116 \\
\hline 600 & 20 & 6.59 & $1.07 \mathrm{E}-06$ & 1.145 & 5.971 & 0.214 \\
\hline 600 & 30 & 7.45 & 5.30E-07 & 1.145 & 6.276 & 0.366 \\
\hline 650 & 20 & 8.79 & 1.43E-06 & 1.083 & 5.846 & 0.414 \\
\hline 650 & 30 & 9.60 & 6.49E-07 & 1.083 & 6.188 & 0.585 \\
\hline 700 & 20 & 10.89 & 1.73E-06 & 1.028 & 5.762 & 0.607 \\
\hline 700 & 30 & 11.66 & 7.55E-07 & 1.028 & 6.122 & 0.787 \\
\hline 750 & 20 & 12.79 & 1.82E-06 & 0.978 & 5.741 & 0.809 \\
\hline 750 & 30 & 13.67 & $1.01 \mathrm{E}-06$ & 0.978 & 5.996 & 0.937 \\
\hline 800 & 20 & 14.77 & 2.05E-06 & 0.932 & 5.689 & 0.976 \\
\hline 800 & 30 & 15.63 & $1.15 \mathrm{E}-06$ & 0.932 & 5.940 & 1.101 \\
\hline 800 & 40 & 16.31 & 7.13E-07 & 0.932 & 6.147 & 1.205 \\
\hline 800 & 120 & 17.49 & 4.32E-07 & 0.932 & 6.364 & 1.313 \\
\hline 700 & 30 & 17.52 & 5.07E-08 & 1.028 & 7.295 & 1.373 \\
\hline 750 & 30 & 17.60 & $1.20 \mathrm{E}-07$ & 0.978 & 6.919 & 1.398 \\
\hline 800 & 30 & 17.82 & $3.48 \mathrm{E}-07$ & 0.932 & 6.459 & 1.360 \\
\hline 850 & 30 & 18.46 & $1.00 \mathrm{E}-06$ & 0.890 & 5.998 & 1.306 \\
\hline 900 & 30 & 19.83 & 2.29E-06 & 0.853 & 5.640 & 1.287 \\
\hline 950 & 30 & 22.20 & 4.34E-06 & 0.818 & 5.362 & 1.296 \\
\hline 1000 & 30 & 26.59 & $9.36 \mathrm{E}-06$ & 0.786 & 5.029 & 1.265 \\
\hline 1050 & 30 & 35.18 & $2.31 \mathrm{E}-05$ & 0.756 & 4.636 & 1.193 \\
\hline 1150 & 30 & 51.86 & 6.34E-05 & 0.703 & 4.198 & 1.199 \\
\hline 1200 & 30 & 78.78 & $1.84 \mathrm{E}-04$ & 0.679 & 3.734 & 1.068 \\
\hline
\end{tabular}

Table 1

Arnaud and Eide, 2000 


\begin{tabular}{|c|c|c|c|c|c|c|c|c|c|c|}
\hline $\begin{array}{l}\text { Temp } \\
{ }^{\circ} \mathrm{C}\end{array}$ & ${ }^{40} \mathrm{Ar} /{ }^{39} \mathrm{Ar}$ & ${ }^{38} \mathrm{Ar} /{ }^{39} \mathrm{Ar}$ & ${ }^{37} \mathrm{Ar} /{ }^{39} \mathrm{Ar}$ & $\begin{array}{c}{ }^{36} \mathrm{Ar}{ }^{39} \mathrm{Ar} \\
\left(10^{-3}\right)\end{array}$ & $\begin{array}{c}{ }^{39} \mathrm{Ar} \\
\left(10^{-14} \text { moles }\right)\end{array}$ & $\begin{array}{c}\mathrm{F}^{39} \mathrm{Ar} \\
\text { released }\end{array}$ & $\%{ }^{40} \mathrm{Ar}^{*}$ & ${ }^{40} \mathrm{Ar} *{ }^{39} \mathrm{Ar}$ & $\begin{array}{l}\text { Age } \\
\text { Ma }\end{array}$ & $\begin{array}{l} \pm 1 \sigma \\
\text { Ма }\end{array}$ \\
\hline 95 AS 3 & & K-feldspar & & $\mathrm{J}=0.0068510$ & & $\mathrm{wt}=4 \mathrm{mg}$ & & & & \\
\hline 400 & 12.089 & 0.039 & 0.004 & 16.843 & 0.14 & 0.58 & 59.29 & 7.17 & 86.48 & 2.04 \\
\hline 400 & 11.598 & 0.031 & 0.017 & 5.585 & 0.08 & 0.91 & 85.73 & 9.94 & 118.89 & 5.94 \\
\hline 450 & 14.227 & 0.025 & 0.001 & 3.045 & 0.30 & 2.14 & 93.53 & 13.31 & 157.40 & 3.07 \\
\hline 450 & 17.439 & 0.023 & 0.007 & 1.908 & 0.23 & 3.09 & 96.62 & 16.85 & 197.08 & 7.26 \\
\hline 500 & 20.428 & 0.022 & 0.004 & 1.467 & 0.48 & 5.06 & 97.74 & 19.97 & 231.30 & 7.16 \\
\hline 500 & 22.177 & 0.022 & 0.004 & 0.643 & 0.33 & 6.42 & 98.99 & 21.95 & 252.78 & 9.10 \\
\hline 550 & 23.431 & 0.022 & 0.003 & 0.740 & 0.56 & 8.73 & 98.93 & 23.18 & 265.90 & 9.33 \\
\hline 550 & 24.193 & 0.022 & 0.003 & 0.000 & 0.36 & 10.20 & 99.85 & 24.16 & 276.29 & 9.23 \\
\hline 600 & 24.788 & 0.022 & 0.001 & 0.500 & 0.47 & 12.13 & 99.26 & 24.61 & 281.04 & 9.61 \\
\hline 600 & 24.812 & 0.022 & 0.003 & 0.000 & 0.38 & 13.70 & 99.85 & 24.78 & 282.84 & 9.41 \\
\hline 650 & 25.188 & 0.022 & 0.002 & 0.280 & 0.46 & 15.57 & 99.53 & 25.07 & 285.94 & 9.54 \\
\hline 650 & 25.098 & 0.022 & 0.002 & 0.000 & 0.34 & 16.96 & 99.85 & 25.06 & 285.86 & 9.31 \\
\hline 700 & 25.472 & 0.022 & 0.002 & 0.282 & 0.42 & 18.70 & 99.53 & 25.35 & 288.94 & 10.00 \\
\hline 700 & 25.200 & 0.021 & 0.002 & 0.000 & 0.33 & 20.04 & 99.85 & 25.16 & 286.93 & 9.31 \\
\hline 750 & 25.791 & 0.022 & 0.003 & 0.344 & 0.42 & 21.76 & 99.47 & 25.65 & 292.10 & 9.24 \\
\hline 750 & 25.428 & 0.022 & 0.002 & 0.000 & 0.31 & 23.01 & 99.85 & 25.39 & 289.33 & 10.18 \\
\hline 800 & 26.218 & 0.022 & 0.007 & 0.442 & 0.43 & 24.76 & 99.37 & 26.05 & 296.29 & 9.79 \\
\hline 800 & 26.221 & 0.022 & 0.004 & 0.000 & 0.36 & 26.24 & 99.86 & 26.18 & 297.66 & 11.02 \\
\hline 800 & 26.378 & 0.022 & 0.003 & 0.000 & 0.31 & 27.50 & 99.86 & 26.34 & 299.31 & 10.68 \\
\hline 800 & 26.744 & 0.023 & 0.003 & 0.000 & 0.54 & 29.73 & 99.86 & 26.71 & 303.13 & 10.83 \\
\hline 700 & 23.852 & 0.006 & 0.005 & 0.000 & 0.01 & 29.77 & 99.85 & 23.82 & 272.66 & 18.94 \\
\hline 750 & 25.837 & 0.023 & 0.004 & 0.000 & 0.03 & 29.91 & 99.86 & 25.80 & 293.63 & 7.76 \\
\hline 800 & 27.231 & 0.023 & 0.005 & 0.000 & 0.09 & 30.28 & 99.86 & 27.19 & 308.22 & 6.06 \\
\hline 850 & 27.838 & 0.023 & 0.005 & 0.000 & 0.25 & 31.31 & 99.87 & 27.80 & 314.53 & 15.18 \\
\hline 900 & 28.528 & 0.024 & 0.009 & 0.447 & 0.48 & 33.29 & 99.42 & 28.36 & 320.35 & 16.17 \\
\hline 1000 & 33.400 & 0.027 & 0.007 & 1.612 & 1.27 & 38.50 & 98.49 & 32.90 & 366.67 & 20.04 \\
\hline 1050 & 34.783 & 0.028 & 0.007 & 2.132 & 1.89 & 46.24 & 98.12 & 34.13 & 379.06 & 18.40 \\
\hline 1100 & 35.382 & 0.029 & 0.005 & 2.323 & 2.93 & 58.28 & 97.99 & 34.67 & 384.49 & 25.33 \\
\hline 1150 & 35.318 & 0.027 & 0.003 & 1.988 & 4.71 & 77.63 & 98.26 & 34.70 & 384.82 & 19.05 \\
\hline 1200 & 35.323 & 0.027 & 0.002 & 1.740 & 5.45 & 100.00 & 98.47 & 34.78 & 385.58 & 30.77 \\
\hline
\end{tabular}

\begin{tabular}{|c|c|c|c|c|c|c|}
\hline $\begin{array}{c}\text { Temp } \\
{ }^{\circ} \mathrm{C}\end{array}$ & $\begin{array}{c}\text { Time } \\
\text { min }\end{array}$ & $\mathrm{f}$ & $\mathrm{D} / \mathrm{r}^{2}$ & $\begin{array}{c}1000 / T \\
\left(K^{-1}\right)\end{array}$ & $-\log \left(\mathrm{D} / \mathrm{r}^{2}\right)$ & $\log \left(r / r_{0}\right)$ \\
\hline \multicolumn{7}{|c|}{$\mathrm{E}=41211 \mathrm{cal} / \mathrm{mol}+-2262 \log (\mathrm{Do} / \mathrm{ro})=5.75 / \mathrm{s}+-0.70$} \\
\hline 400 & 20 & 0.58 & 2.18E-08 & 1.486 & 7.661 & 0.014 \\
\hline 400 & 30 & 0.91 & 2.14E-08 & 1.486 & 7.669 & 0.018 \\
\hline 450 & 20 & 2.14 & 2.47E-07 & 1.383 & 6.608 & -0.050 \\
\hline 450 & 30 & 3.09 & $2.16 \mathrm{E}-07$ & 1.383 & 6.666 & -0.021 \\
\hline 500 & 20 & 5.06 & 1.05E-06 & 1.294 & 5.977 & 0.038 \\
\hline 500 & 30 & 6.42 & 6.81E-07 & 1.294 & 6.167 & 0.133 \\
\hline 550 & 20 & 8.73 & 2.29E-06 & 1.215 & 5.640 & 0.223 \\
\hline 550 & 30 & 10.20 & $1.21 \mathrm{E}-06$ & 1.215 & 5.917 & 0.361 \\
\hline 600 & 20 & 12.13 & 2.82E-06 & 1.145 & 5.549 & 0.491 \\
\hline 600 & 30 & 13.70 & 1.77E-06 & 1.145 & 5.753 & 0.593 \\
\hline 650 & 20 & 15.57 & 3.59E-06 & 1.083 & 5.445 & 0.718 \\
\hline 650 & 30 & 16.96 & 1.98E-06 & 1.083 & 5.704 & 0.847 \\
\hline 700 & 20 & 18.70 & 4.06E-06 & 1.028 & 5.392 & 0.942 \\
\hline 700 & 30 & 20.04 & $2.26 \mathrm{E}-06$ & 1.028 & 5.646 & 1.069 \\
\hline 750 & 20 & 21.76 & 4.70E-06 & 0.978 & 5.328 & 1.137 \\
\hline 750 & 30 & 23.01 & $2.45 \mathrm{E}-06$ & 0.978 & 5.611 & 1.278 \\
\hline 800 & 20 & 24.76 & 5.48E-06 & 0.932 & 5.261 & 1.308 \\
\hline 800 & 30 & 26.24 & 3.29E-06 & 0.932 & 5.483 & 1.419 \\
\hline 800 & 40 & 27.50 & 2.22E-06 & 0.932 & 5.654 & 1.504 \\
\hline 800 & 120 & 29.73 & 1.39E-06 & 0.932 & 5.857 & 1.606 \\
\hline 700 & 30 & 29.77 & 1.09E-07 & 1.028 & 6.963 & 1.728 \\
\hline 750 & 30 & 29.91 & $3.54 \mathrm{E}-07$ & 0.978 & 6.450 & 1.698 \\
\hline 800 & 30 & 30.28 & $9.86 \mathrm{E}-07$ & 0.932 & 6.006 & 1.681 \\
\hline 850 & 30 & 31.31 & 2.75E-06 & 0.890 & 5.561 & 1.645 \\
\hline 900 & 30 & 33.29 & 5.59E-06 & 0.853 & 5.253 & 1.662 \\
\hline 1000 & 30 & 38.50 & 1.63E-05 & 0.786 & 4.787 & 1.730 \\
\hline 1050 & 30 & 46.24 & 2.86E-05 & 0.756 & 4.543 & 1.742 \\
\hline 1100 & 30 & 58.28 & 5.49E-05 & 0.728 & 4.260 & 1.725 \\
\hline 1150 & 30 & 77.63 & $1.42 \mathrm{E}-04$ & 0.703 & 3.849 & 1.634 \\
\hline
\end{tabular}

Table 1 cont

Arnaud and Eide, 2000 


\begin{tabular}{|c|c|c|c|c|c|c|c|c|c|c|}
\hline $\begin{array}{l}\text { Temp } \\
{ }^{\circ} \mathrm{C}\end{array}$ & ${ }^{40} \mathrm{Ar} /{ }^{39} \mathrm{Ar}$ & ${ }^{38} \mathrm{Ar} /{ }^{39} \mathrm{Ar}$ & ${ }^{37} \mathrm{Ar} /{ }^{39} \mathrm{Ar}$ & $\begin{array}{c}{ }^{36} \mathrm{Ar} /{ }^{39} \mathrm{Ar} \\
\left(10^{-3}\right)\end{array}$ & $\begin{array}{c}{ }^{39} \mathrm{Ar} \\
\left(10^{-14} \mathrm{moles}\right)\end{array}$ & $\begin{array}{c}\mathrm{F}^{39} \mathrm{Ar} \\
\text { released }\end{array}$ & $\%{ }^{40} \mathrm{Ar}^{*}$ & ${ }^{40} \mathrm{Ar} *{ }^{39} \mathrm{Ar}$ & $\begin{array}{l}\text { Age } \\
\text { Ma }\end{array}$ & $\begin{array}{l} \pm 1 \sigma \\
\mathrm{Ma}\end{array}$ \\
\hline 95 AS 4B & & K-feldspar & & $\mathrm{J}=0.0068510$ & & $\mathrm{wt}=1 \mathrm{mg}$ & & & & \\
\hline 400 & 99.804 & 0.150 & 0.000 & 340.632 & 0.05 & 1.76 & 0.99 & 0.98 & 12.12 & 3.13 \\
\hline 400 & 25.111 & 0.054 & 0.467 & 68.520 & 0.07 & 4.25 & 20.91 & 5.25 & 63.79 & 3.46 \\
\hline 450 & 15.982 & 0.033 & 0.343 & 21.855 & 0.13 & 8.91 & 60.33 & 9.65 & 115.46 & 2.52 \\
\hline 450 & 19.159 & 0.029 & 0.000 & 17.887 & 0.12 & 13.33 & 72.73 & 13.93 & 164.49 & 3.62 \\
\hline 500 & 20.525 & 0.025 & 0.000 & 8.539 & 0.24 & 22.22 & 87.75 & 18.01 & 209.91 & 4.01 \\
\hline 500 & 23.907 & 0.025 & 0.000 & 7.625 & 0.20 & 29.77 & 90.59 & 21.66 & 249.59 & 4.78 \\
\hline 550 & 26.667 & 0.025 & 0.628 & 9.971 & 0.31 & 41.19 & 89.26 & 23.82 & 272.76 & 5.87 \\
\hline 550 & 28.765 & 0.025 & 0.703 & 13.205 & 0.19 & 48.32 & 86.81 & 25.00 & 285.17 & 6.30 \\
\hline 600 & 33.016 & 0.028 & 1.148 & 28.931 & 0.19 & 55.29 & 74.83 & 24.75 & 282.55 & 6.47 \\
\hline 600 & 35.358 & 0.030 & 1.187 & 33.550 & 0.11 & 59.52 & 72.72 & 25.76 & 293.19 & 7.14 \\
\hline 650 & 28.163 & 0.026 & 1.725 & 10.110 & 0.15 & 64.97 & 90.08 & 25.43 & 289.79 & 6.26 \\
\hline 650 & 30.513 & 0.027 & 1.175 & 13.623 & 0.10 & 68.56 & 87.32 & 26.69 & 302.97 & 7.06 \\
\hline 700 & 30.612 & 0.024 & 0.078 & 10.875 & 0.08 & 71.44 & 89.60 & 27.43 & 310.70 & 7.00 \\
\hline 700 & 31.069 & 0.028 & 0.000 & 11.185 & 0.07 & 73.91 & 89.44 & 27.79 & 314.39 & 6.80 \\
\hline 750 & 30.693 & 0.026 & 0.000 & 8.558 & 0.08 & 76.88 & 91.79 & 28.17 & 318.40 & 7.21 \\
\hline 750 & 30.197 & 0.029 & 0.708 & 8.660 & 0.07 & 79.36 & 91.80 & 27.75 & 313.99 & 6.86 \\
\hline 800 & 27.777 & 0.029 & 1.186 & 8.356 & 0.07 & 82.11 & 91.57 & 25.48 & 290.29 & 6.72 \\
\hline 800 & 26.999 & 0.031 & 0.836 & 2.614 & 0.04 & 83.70 & 97.37 & 26.32 & 299.11 & 8.78 \\
\hline 800 & 28.945 & 0.031 & 0.287 & 0.129 & 0.03 & 84.80 & 99.84 & 28.91 & 326.02 & 12.98 \\
\hline 800 & 30.883 & 0.041 & 0.133 & 5.290 & 0.05 & 86.62 & 94.96 & 29.33 & 330.34 & 21.64 \\
\hline 800 & 36.527 & 0.053 & 4.189 & 8.020 & 0.01 & 86.81 & 94.69 & 34.81 & 385.85 & 47.15 \\
\hline 850 & 29.826 & 0.036 & 0.296 & 6.880 & 0.02 & 87.38 & 93.29 & 27.84 & 314.90 & 22.53 \\
\hline 900 & 26.812 & 0.034 & 0.765 & 8.149 & 0.03 & 88.51 & 91.34 & 24.52 & 280.11 & 14.85 \\
\hline 950 & 25.419 & 0.035 & 0.852 & 9.722 & 0.04 & 89.91 & 89.10 & 22.68 & 260.53 & 14.41 \\
\hline 1000 & 29.989 & 0.040 & 0.000 & 26.783 & 0.03 & 90.93 & 73.98 & 22.18 & 255.25 & 23.45 \\
\hline 1050 & 26.099 & 0.036 & 0.276 & 24.130 & 0.04 & 92.24 & 73.15 & 19.10 & 221.86 & 20.78 \\
\hline 1100 & 25.336 & 0.027 & 0.000 & 19.265 & 0.08 & 95.14 & 77.80 & 19.71 & 228.53 & 11.11 \\
\hline 1150 & 20.462 & 0.027 & 0.000 & 21.358 & 0.09 & 98.60 & 69.55 & 14.23 & 167.83 & 9.92 \\
\hline 1200 & 45.151 & 0.057 & 0.100 & 117.098 & 0.02 & 99.46 & 24.73 & 11.17 & 132.99 & 68.73 \\
\hline 1400 & 277.069 & 0.234 & 11.117 & 985.658 & 0.01 & 100.00 & -2.77 & -7.81 & 0.00 & 0.00 \\
\hline
\end{tabular}

\begin{tabular}{|c|c|c|c|c|c|c|}
\hline $\begin{array}{c}\text { Temp } \\
{ }^{\circ} \mathrm{C} \\
\mathrm{E}=42716\end{array}$ & $\begin{array}{c}\text { Time } \\
\text { min } \\
\text { mol +- }\end{array}$ & $9 \log (\mathrm{I}$ & $\mathrm{ro})=7.46 / \mathrm{s}$ & $\begin{array}{c}1000 / \mathrm{T} \\
\left(\mathrm{K}^{-1}\right) \\
-1.90\end{array}$ & $-\log \left(\mathrm{D} / \mathrm{r}^{2}\right)$ & $\log \left(r / r_{0}\right)$ \\
\hline 400 & 20 & 1.76 & 2.04E-07 & 1.486 & 6.691 & 0.142 \\
\hline 400 & 30 & 4.25 & 6.52E-07 & 1.486 & 6.186 & -0.111 \\
\hline 450 & 20 & 8.91 & 4.02E-06 & 1.383 & 5.396 & -0.026 \\
\hline 450 & 30 & 13.33 & 4.28E-06 & 1.383 & 5.368 & -0.040 \\
\hline 500 & 20 & 22.22 & 2.07E-05 & 1.294 & 4.684 & 0.035 \\
\hline 500 & 30 & 29.77 & $1.71 \mathrm{E}-05$ & 1.294 & 4.766 & 0.076 \\
\hline 550 & 20 & 41.19 & 5.30E-05 & 1.215 & 4.275 & 0.198 \\
\hline 550 & 30 & 48.32 & 2.78E-05 & 1.215 & 4.556 & 0.338 \\
\hline 600 & 20 & 55.29 & 4.73E-05 & 1.145 & 4.325 & 0.547 \\
\hline 600 & 30 & 59.52 & 2.12E-05 & 1.145 & 4.674 & 0.722 \\
\hline 650 & 20 & 64.97 & 5.15E-05 & 1.083 & 4.288 & 0.818 \\
\hline 650 & 30 & 68.56 & $2.44 \mathrm{E}-05$ & 1.083 & 4.613 & 0.981 \\
\hline 700 & 20 & 71.44 & $3.25 \mathrm{E}-05$ & 1.028 & 4.489 & 1.179 \\
\hline 700 & 30 & 73.91 & 2.03E-05 & 1.028 & 4.692 & 1.280 \\
\hline 750 & 20 & 76.88 & 4.09E-05 & 0.978 & 4.388 & 1.362 \\
\hline 750 & 30 & 79.36 & 2.55E-05 & 0.978 & 4.593 & 1.465 \\
\hline 800 & 20 & 82.11 & 4.83E-05 & 0.932 & 4.316 & 1.539 \\
\hline 800 & 30 & 83.70 & $2.10 \mathrm{E}-05$ & 0.932 & 4.679 & 1.720 \\
\hline 800 & 40 & 84.80 & 1.17E-05 & 0.932 & 4.931 & 1.846 \\
\hline 800 & 120 & 86.62 & 7.18E-06 & 0.932 & 5.144 & 1.953 \\
\hline 800 & 30 & 86.81 & 3.33E-06 & 0.932 & 5.477 & 2.120 \\
\hline 850 & 30 & 87.38 & 9.97E-06 & 0.890 & 5.001 & 2.075 \\
\hline 900 & 30 & 88.51 & 2.10E-05 & 0.853 & 4.677 & 2.091 \\
\hline 950 & 30 & 89.91 & 2.92E-05 & 0.818 & 4.535 & 2.182 \\
\hline 1000 & 30 & 90.93 & 2.42E-05 & 0.786 & 4.616 & 2.372 \\
\hline 1050 & 30 & 92.24 & 3.51E-05 & 0.756 & 4.455 & 2.430 \\
\hline 1100 & 30 & 95.14 & 1.05E-04 & 0.728 & 3.977 & 2.320 \\
\hline 1150 & 30 & 98.60 & $2.80 \mathrm{E}-04$ & 0.703 & 3.553 & 2.227 \\
\hline 1200 & 30 & 99.46 & $2.14 \mathrm{E}-04$ & 0.679 & 3.670 & 2.397 \\
\hline
\end{tabular}

Table 1 cont

Arnaud and Eide, 2000 


\begin{tabular}{|c|c|c|c|}
\hline $\begin{array}{r}\text { Sample number, } \\
\text { modelling activation } \\
\text { energy and frequency factor }\end{array}$ & $\begin{array}{l}\text { Domain from less } \\
\text { to most retentive }\end{array}$ & $\begin{array}{c}\text { Relative } \\
\text { volume faction }\end{array}$ & $\begin{array}{l}\text { Domain size relative } \\
\text { to the most retentive }\end{array}$ \\
\hline \multirow{5}{*}{$\begin{array}{r}\text { 95As1 } \\
\mathrm{E}=46.49 \mathrm{kcal} / \mathrm{mol} \\
\log \mathrm{D}_{\mathrm{o}} / \mathrm{r}^{2}=6.63 \mathrm{~m}^{2} / \mathrm{s}\end{array}$} & 1 & 0.02412 & 0.00037 \\
\hline & 2 & 0.0402 & 0.00221 \\
\hline & 3 & 0.04846 & 0.0098 \\
\hline & 4 & 0.30525 & 0.76642 \\
\hline & 5 & 0.58197 & 1 \\
\hline \multirow{5}{*}{$\begin{array}{r}\text { 95As3 } \\
\mathrm{E}=46.60 \mathrm{kcal} / \mathrm{mol} \\
\log \mathrm{D}_{\mathrm{o}} / \mathrm{r}^{2}=7.42 \mathrm{~m}^{2} / \mathrm{s}\end{array}$} & 1 & 0.06812 & 0.00071 \\
\hline & 2 & 0.07705 & 0.00504 \\
\hline & 3 & 0.08039 & 0.03168 \\
\hline & 4 & 0.74055 & 0.95 \\
\hline & 5 & 0.03389 & 1 \\
\hline \multirow{8}{*}{$\begin{array}{r}\text { 95As4b } \\
\mathrm{E}=44.81 \mathrm{kcal} / \mathrm{mol} \\
\log \mathrm{D}_{\mathrm{o}} / \mathrm{r}^{2}=8.15 \mathrm{~m}^{2} / \mathrm{s}\end{array}$} & 1 & 0.03863 & 0.00037 \\
\hline & 2 & 0.16146 & 0.00116 \\
\hline & 3 & 0.13493 & 0.00256 \\
\hline & 4 & 0.12602 & 0.00294 \\
\hline & 5 & 0.18977 & 0.00993 \\
\hline & 6 & 0.14464 & 0.04559 \\
\hline & 7 & 0.06772 & 0.14916 \\
\hline & 8 & 0.13682 & 1 \\
\hline
\end{tabular}

Table 2

Arnaud and Eide, 2000 


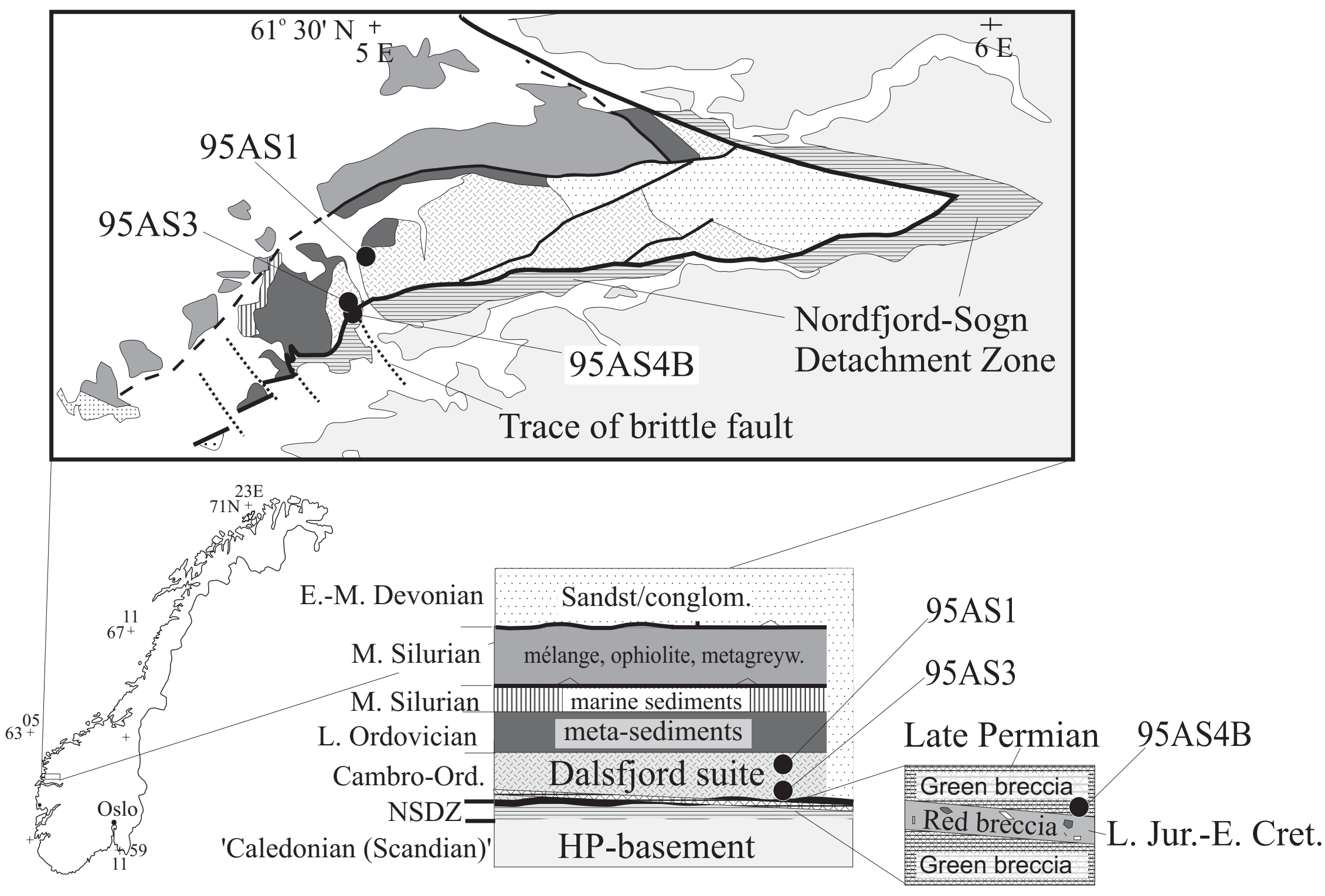

Brittle fault

Figure 1

(Arnaud \& Eide) 

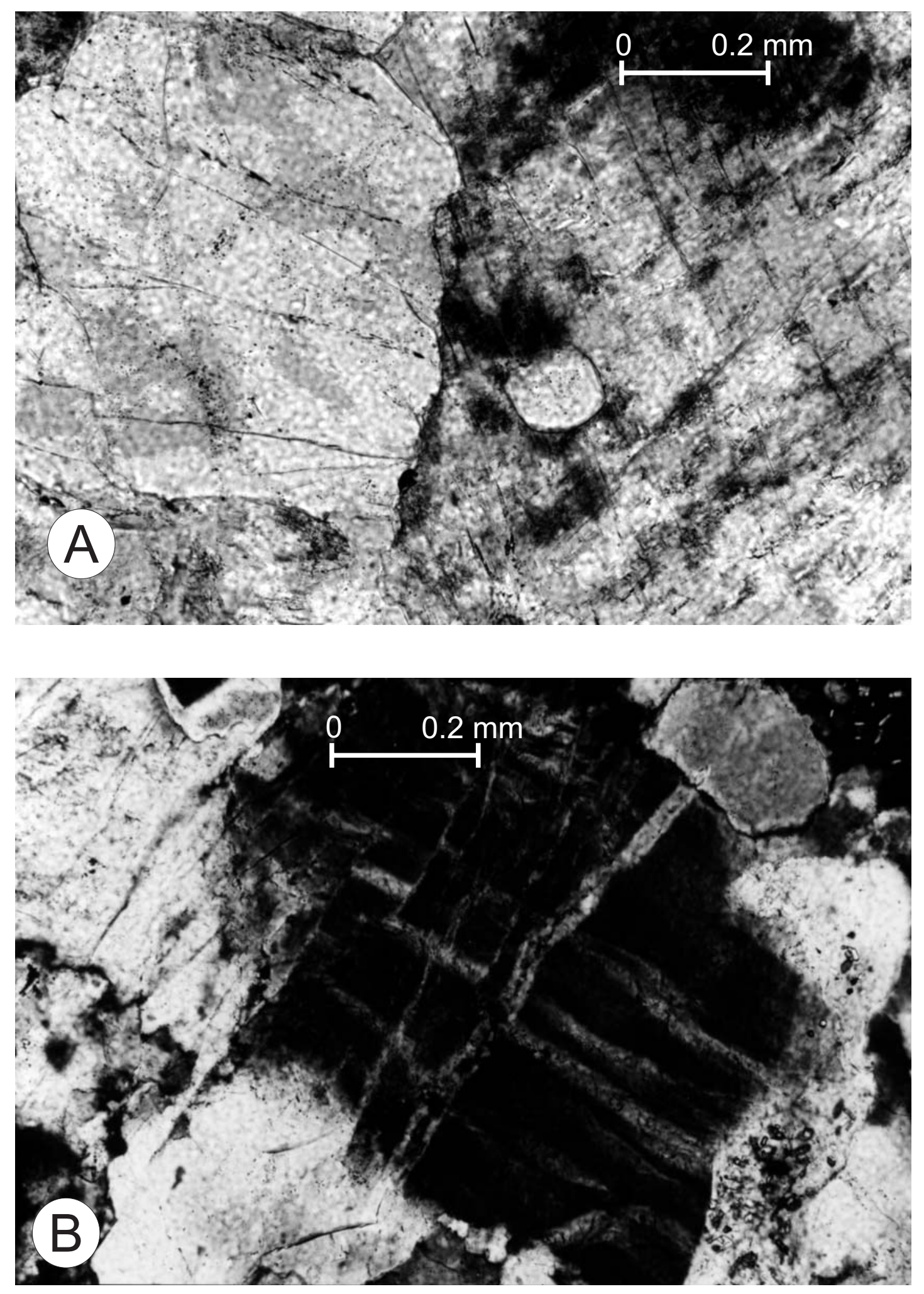

Figure 2, Arnaud and Eide, 2000 

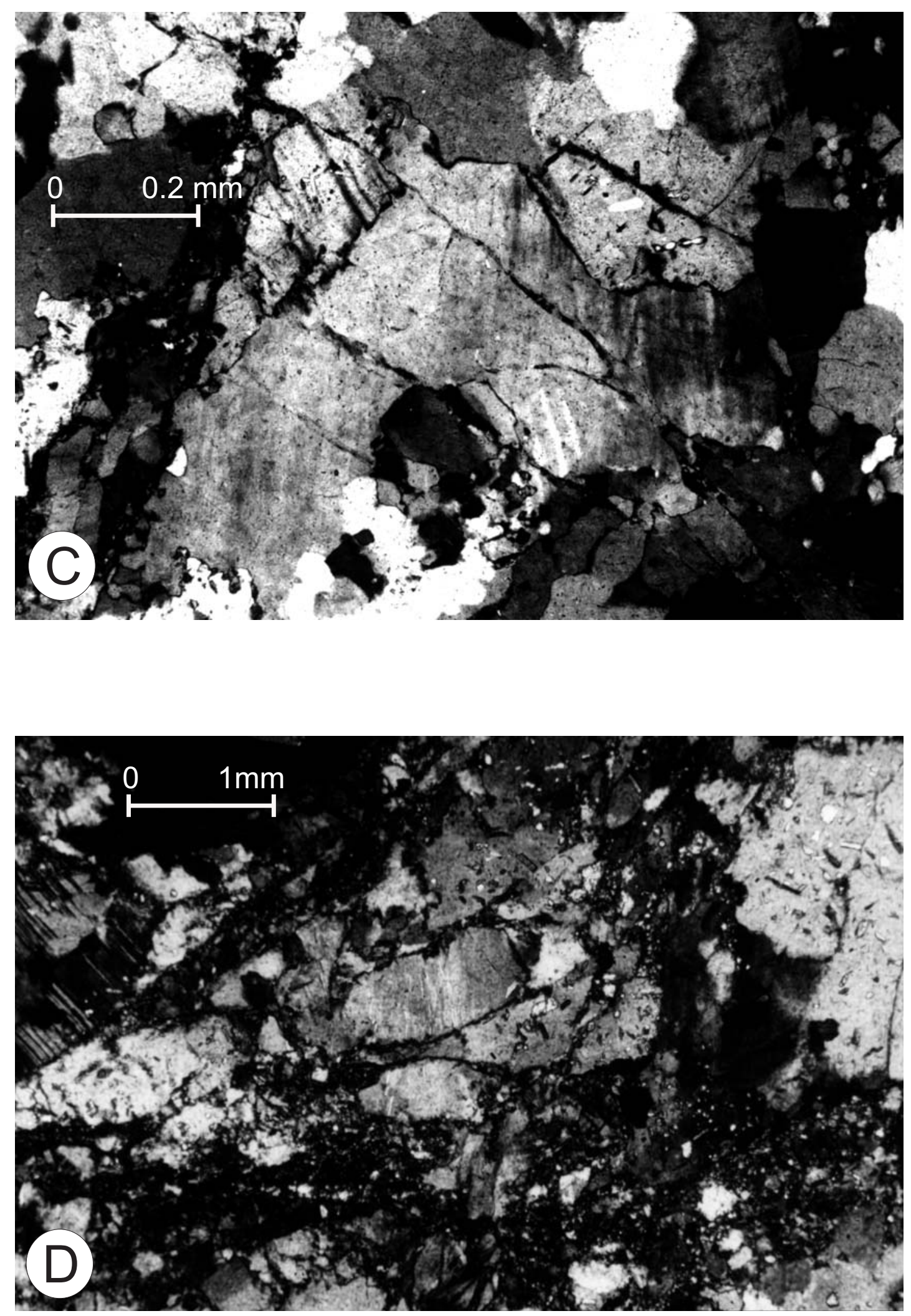

Figure 2, Arnaud and Eide, 2000 


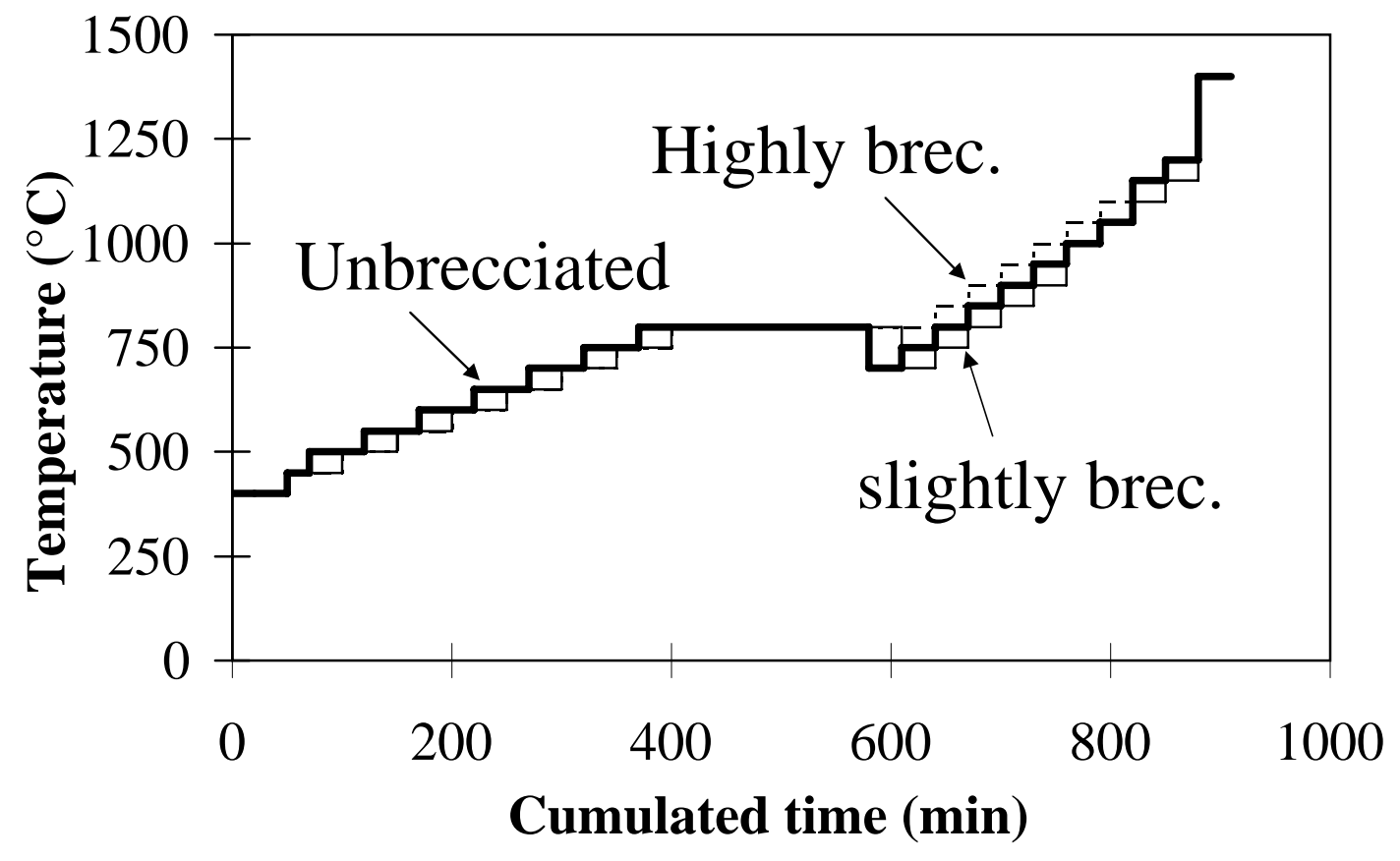

Figure 3

Arnaud and Eide, 2000 
A: Unbrecciated sample 95As1
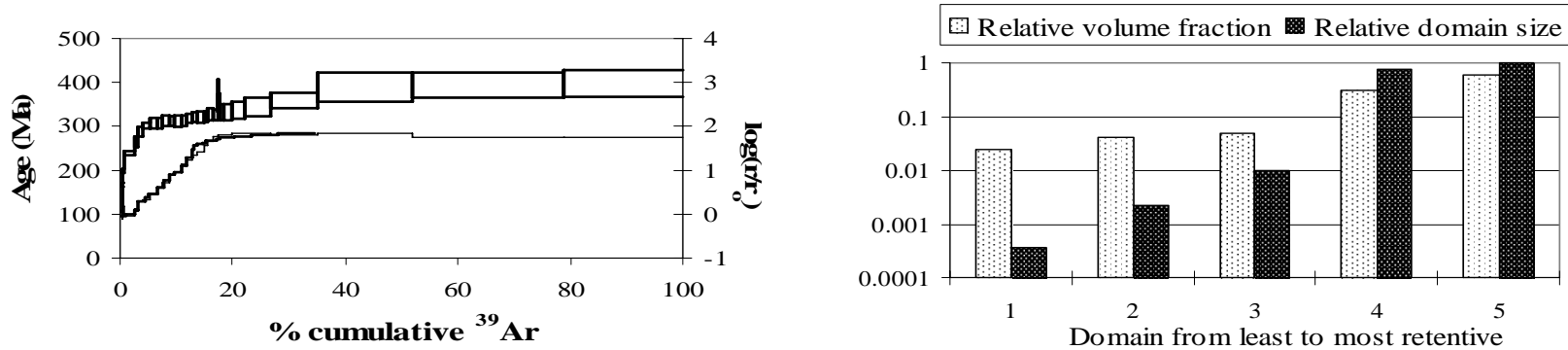

B: Slightly brecciated sample 95As3

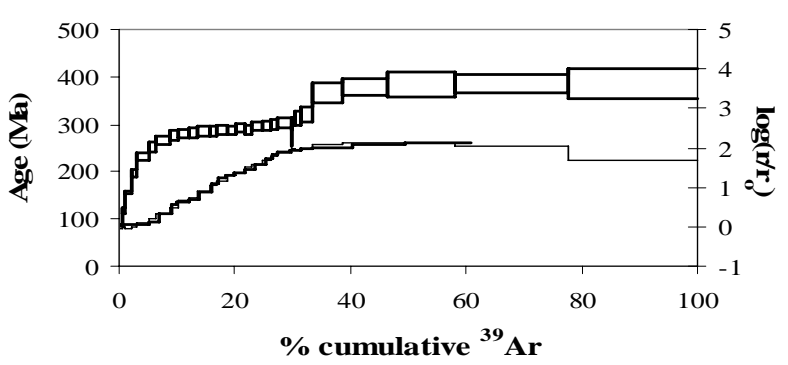

Relative volume fraction Relative domain size

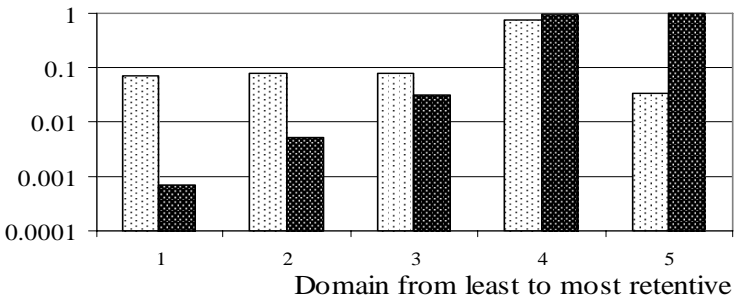

C: Highly brecciated sample 95As4B

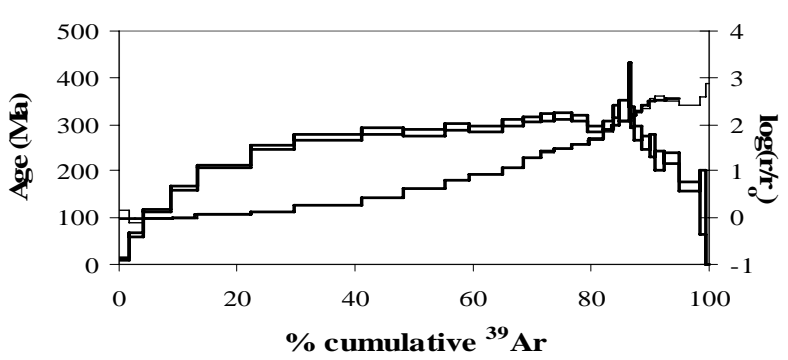

— Relative volume fraction Relative domain size

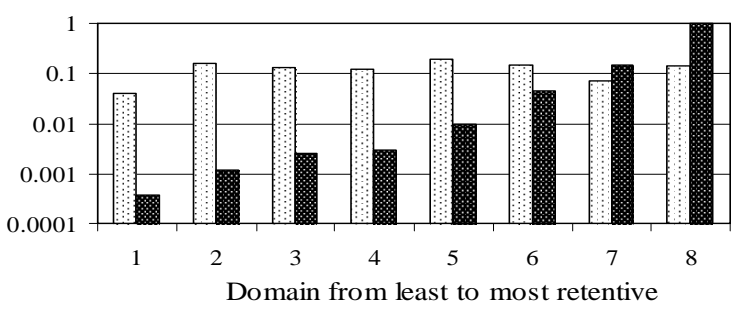

Figure 4

Arnaud and Eide, 2000 
A: Unbrecciated sample 95As1

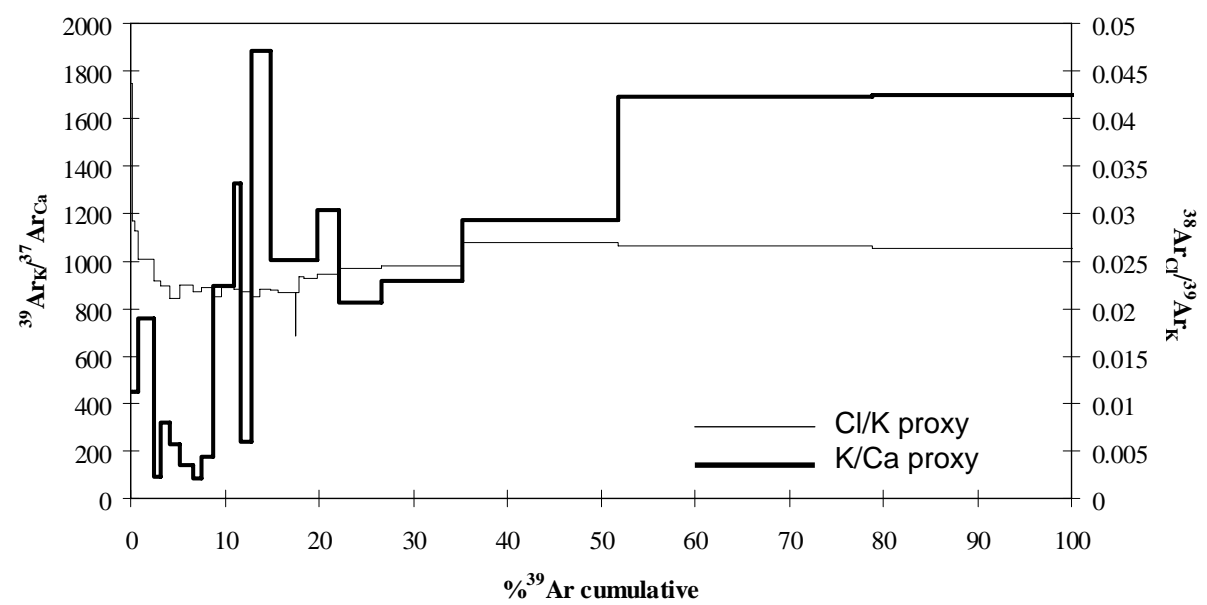

B: Slightly brecciated sample 95As3

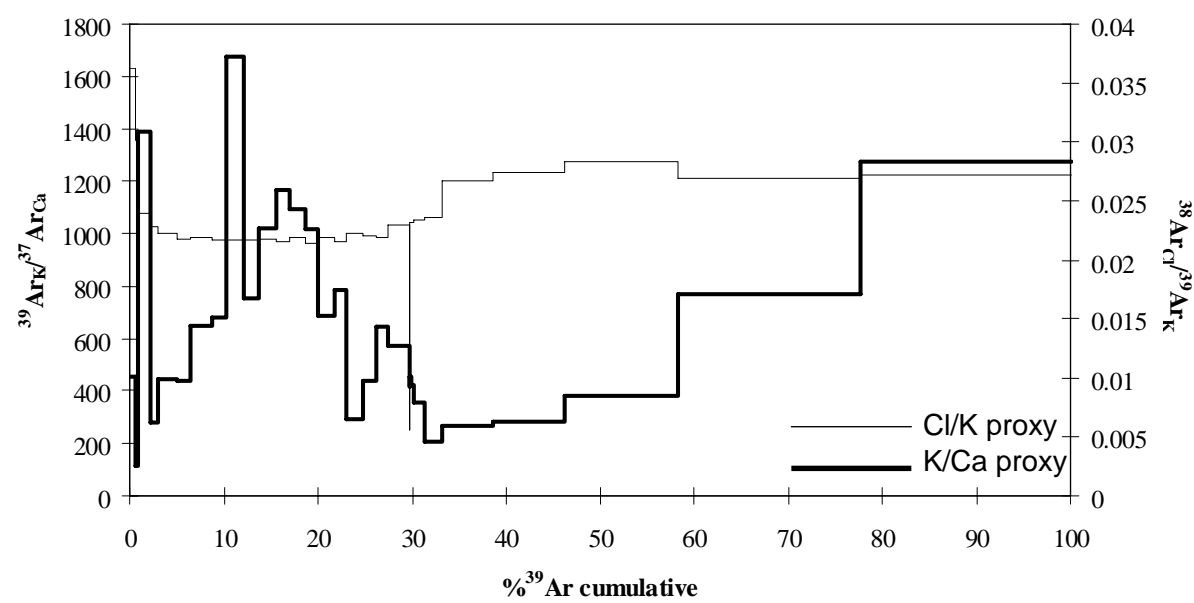

C: Highly brecciated sample 95As4B

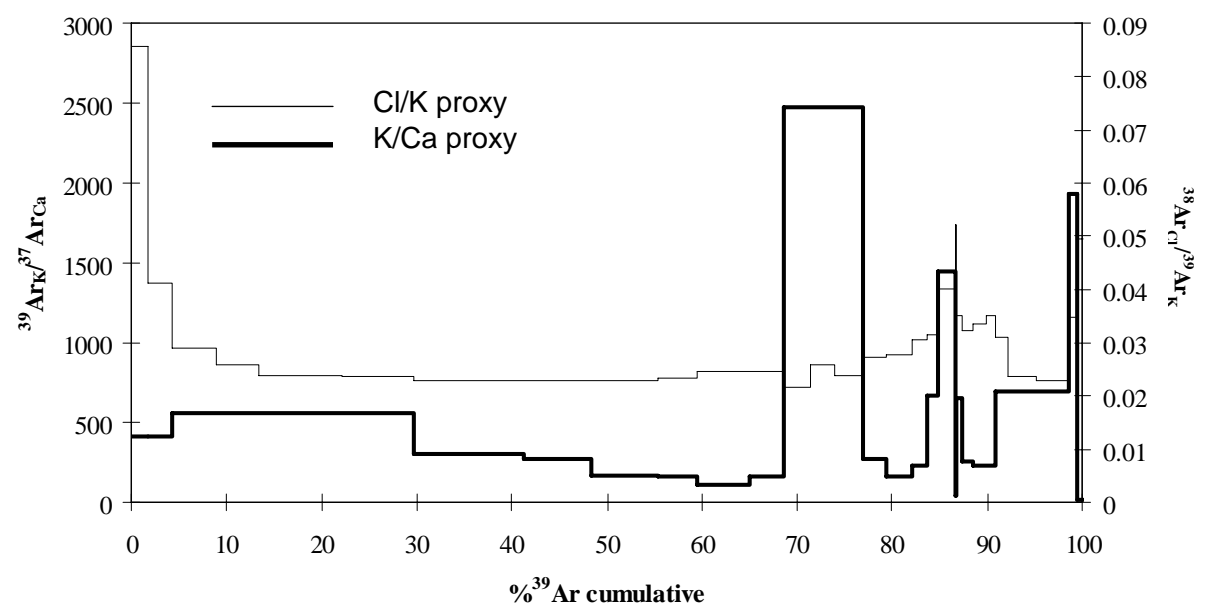

Figure 5

Arnaud and Eide, 2000 


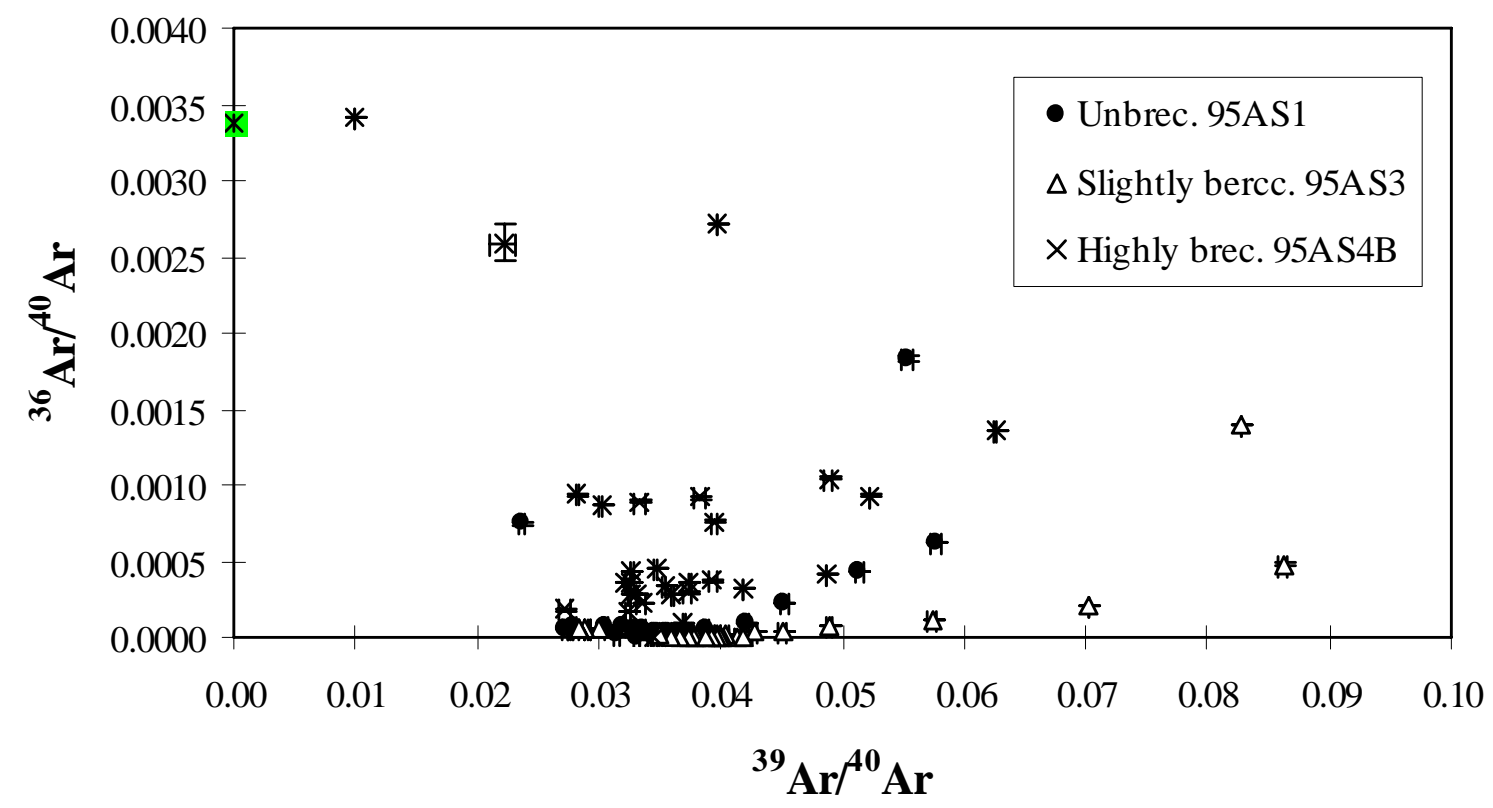

Figure 6

Arnaud and Eide, 2000 
A. Post-Caledonian/pre Permian, ca. $250^{\circ} \mathrm{C}$

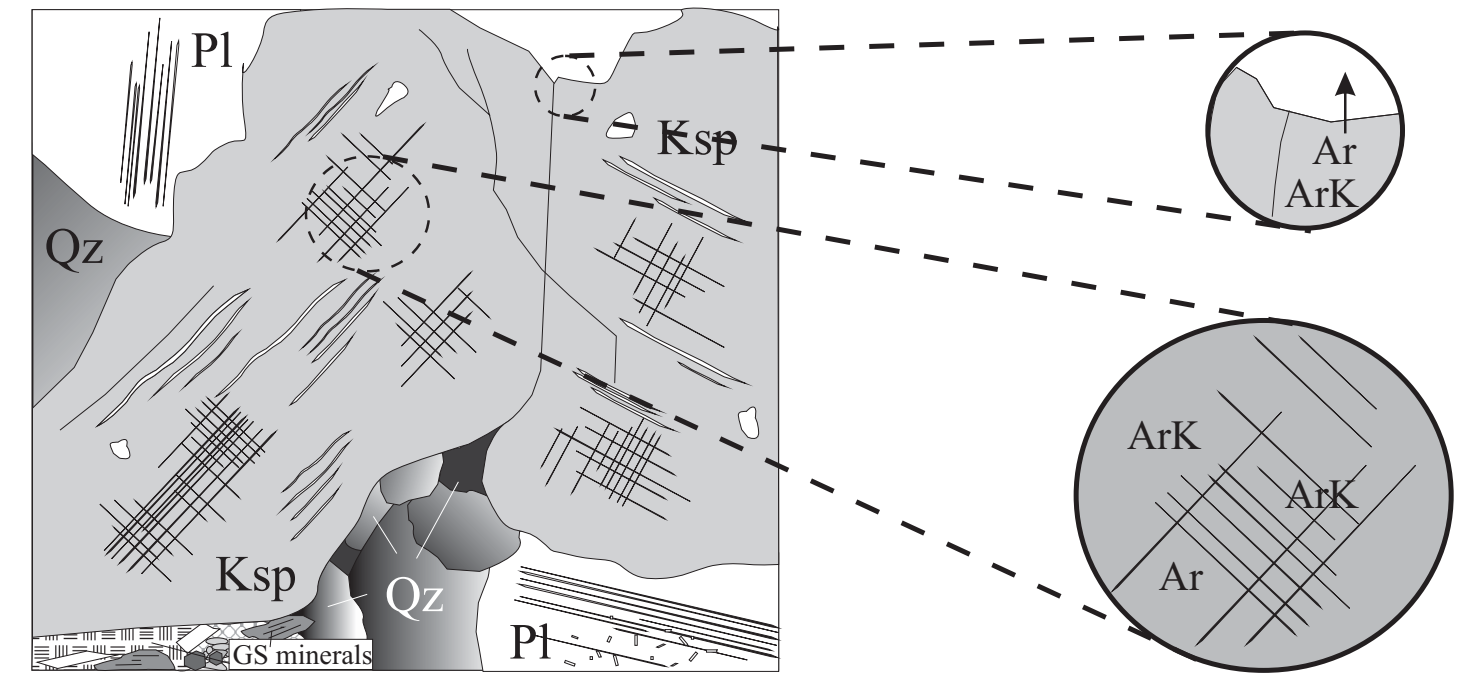

\section{AS1: Top-west extensional collapse (NSDZ)}

ArK is on going in situ production of radiogenic $\mathrm{Ar}$ Ar is Ar having been inherited or produced in situ

Fig 7a.

Arnaud \& Eide 
B. ca. $260 \mathrm{Ma} /$ ca. $225^{\circ} \mathrm{C}$

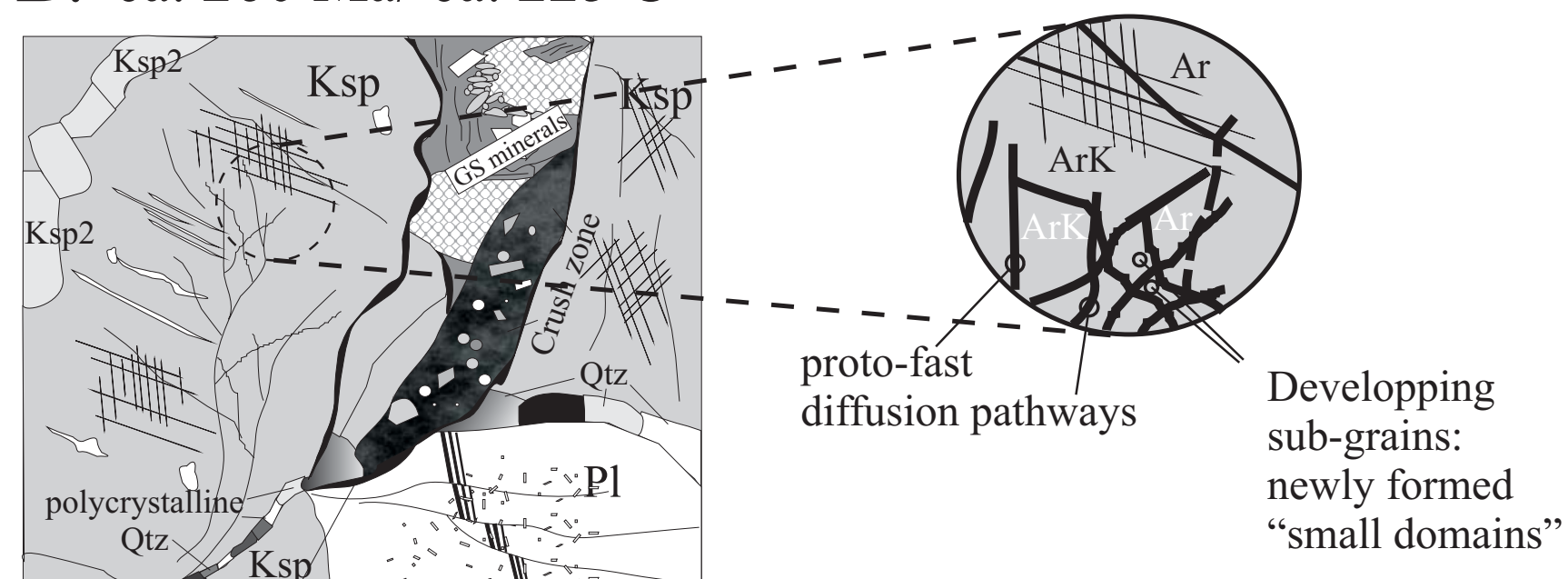

Ave $\mathbb{K}$ is on going in situ

production of radiogenic Ar in newly formed small domains (deformation subgrains)

Ave is Ar having been inherited or produced in situ now residing in newly formed small domains

Fig. $7 b$

Arnaud \& Eide 
C.ca. $250 \mathrm{Ma} / \mathrm{ca} .200^{\circ} \mathrm{C}$

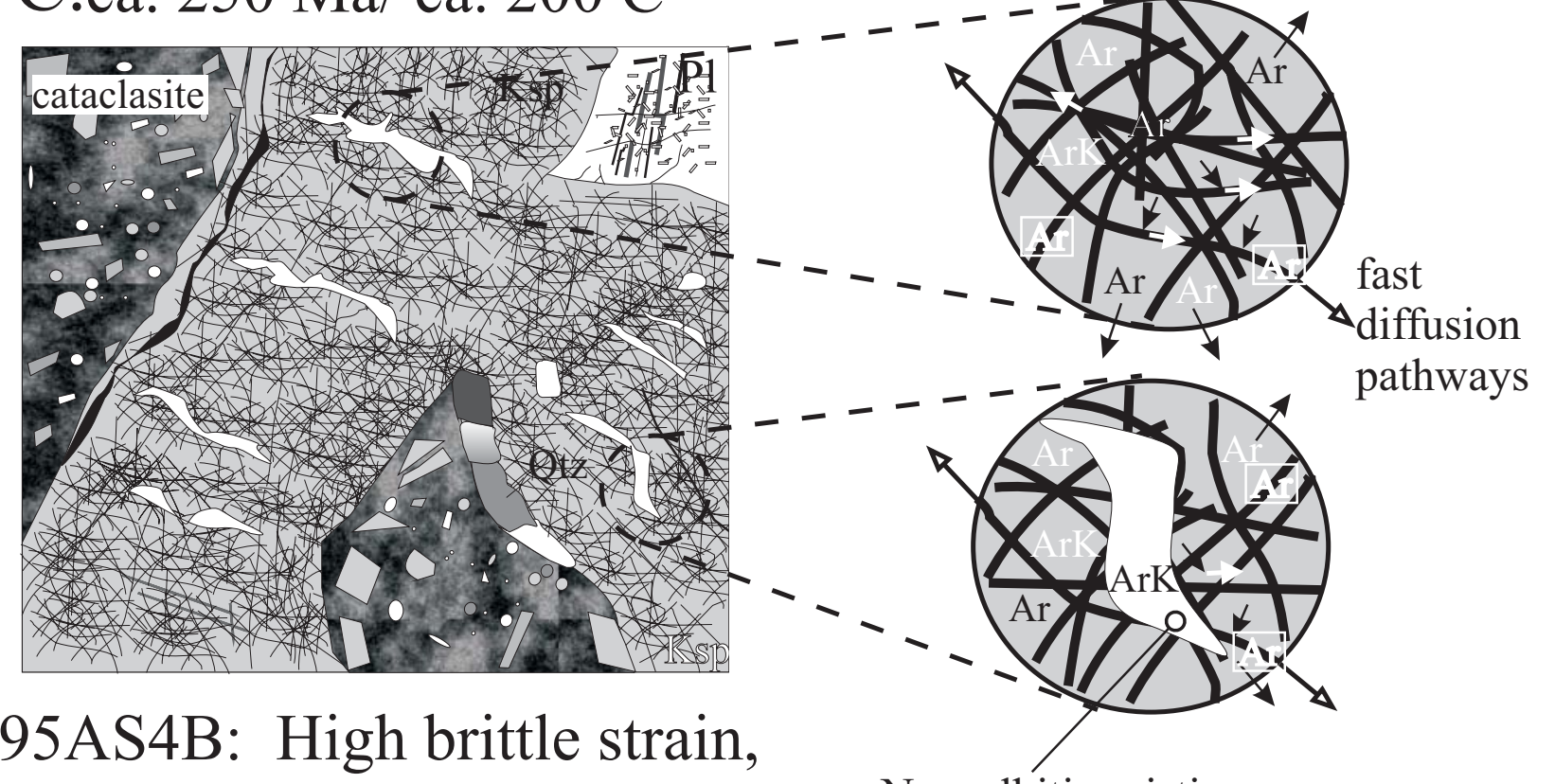
extensional brittle faulting, fluid flow, cataclasis

New albitic pristine crystals

Art is Ar being transferred from the lattice (both original and newly formed domains) to, and lost from, fast diffusion pathways

Fig. 7c

Arnaud \& Eide 